3

4 5

6

7

8

9

10

11

12

13

14

15

16

\title{
Mechanism for Si Poisoning of Al-Ti-B Grain Refiners in Al-Alloys
}

Yun Wang ${ }^{\mathrm{a}}$, Zhongping Que ${ }^{\mathrm{a}}$, Teruo Hashimoto ${ }^{\mathrm{b}}$, Xiaorong Zhou ${ }^{\mathrm{b}}$, Zhongyun Fan ${ }^{\mathrm{a} *}$ a BCAST, Brunel University London, Uxbridge, Middlesex, UB8 3PH, UK

b School of Materials, University of Manchester, Manchester, M13 9PL, UK

* Corresponding author:

Professor Zhongyun Fan

BCAST, Brunel University London,

Uxbridge UB8 3PH, UK

Tel: +44 1895266406

Email: zhongyun.fan@brunel.ac.uk 


\section{Abstract}

Al-5Ti-1B is the most widely used grain refiner for Al-alloys. However, it is not effective for grain refining $\mathrm{Al}$-alloys containing more than $3 \mathrm{wt} . \% \mathrm{Si}$. This adverse effect of $\mathrm{Si}$ is referred to as Si poisoning. In spite of extensive experimental and theoretical investigations in the past decades, the exact mechanism for Si poisoning is still not clear. In this work, the state-of-theart electron microscopy was performed to investigate the mechanism for Si poisoning. Our experimental results suggest that $\mathrm{Si}$ segregates preferably to the $\mathrm{TiB}_{2} / \mathrm{Al}-\mathrm{Si}$ melt interface and the pre-existing $\mathrm{Al}_{3} \mathrm{Ti}$ 2-dimensional compound (2DC) layer on $\mathrm{TiB}_{2}$ surface dissolves into the Al-Si melt. Based on the experimental results, we have postulated a new mechanism for Si poisoning: interfacial segregation of $\mathrm{Si}$ leads to enrichment of $\mathrm{Si}$ at the $\mathrm{TiB}_{2} / \mathrm{Al}-\mathrm{Si}$ melt interface, and this in turn makes the pre-existing $\mathrm{Al}_{3} \mathrm{Ti} 2 \mathrm{DC}$ on the $\mathrm{TiB}_{2}$ surface unstable and dissolve gradually in the melt, resulting in a loss of $\mathrm{TiB}_{2}$ nucleation potency and hence a decreased total number of potent $\mathrm{TiB}_{2}$ particles available for heterogeneous nucleation and grain initiation and consequently an increased grain size. This mechanism for Si poisoning can explain consistently the experimentally observed phenomenon reported in the literature.

Keywords: Solidification; Heterogeneous nucleation; Grain refinement; Si poisoning.

\section{Introduction}

A grain refined microstructure is usually desirable for Al-alloy castings, since it not only facilitates the casting processes, but also improves mechanical performance of the alloys through reduced cast defects, such as macro-segregation, hot tearing and porosity. In the Al industry, a common foundry practice for grain refinement is addition of grain refiner prior to casting processes, with Al-5Ti-1B (all the alloy compositions are in wt.\% unless stated otherwise) being the most widely used commercial grain refiner. Since the introduction of AlTi-B based grain refiners in early 1950s, [1] extensive experimental investigations and theoretical studies have been carried out to understand the underpinning mechanisms for grain refinement. [2-7] It is now generally accepted that promoting heterogeneous nucleation of numerous $\alpha \mathrm{Al}$ grains on $\mathrm{TiB}_{2}$ particles is responsible for grain refinement. Various hypotheses have been proposed to explain the mechanisms of heterogeneous nucleation in the $\mathrm{Al}_{-} \mathrm{TiB}_{2}$ system. [3-7] It is only until very recently to realize that the formation of an atomic layer of $\mathrm{Al}_{3} \mathrm{Ti}$ 2-dimensional compound (2DC) on the $\left(\begin{array}{llll}0 & 0 & 0 & 1\end{array}\right) \mathrm{TiB}_{2}$ surface is responsible for the high potency of the $\mathrm{TiB}_{2}$ particles for nucleation of $\alpha \mathrm{Al}$ grains. [8]

The presence of alloying elements has long been recognized as one of the important factors for grain refinement by providing growth restriction. However, this may not be true for all the elements. For instance, Al-5Ti-1B becomes ineffective for grain refinement when certain elements are present in the alloy melt, such as $\mathrm{Zr}$, [9-14] Li, [15-16] Cr, [17-18] and high levels of Si. [19-34] The negative effect of solute elements on grain refinement is referred to as "poisoning" in the literature. One of the main explanations to the poisoning effect is that the 
interaction between solute elements and $\mathrm{TiB}_{2}$ particles leads to the decrease in nucleation potency of the $\mathrm{TiB}_{2}$ particles. [35] Our recent research work on $\mathrm{Zr}$ poisoning disclosed that the presence of $\mathrm{Zr}$ in the melt results in the dissolution of the pre-existing $\mathrm{Al}_{3} \mathrm{Ti} 2 \mathrm{DC}$ layer (formed during the grain refiner production process) and the formation of a $\mathrm{Ti}_{2} \mathrm{Zr} 2 \mathrm{DC}$ atomic layer on $\mathrm{TiB}_{2}$ surface, which is responsible for the reduced potency of $\mathrm{TiB}_{2}$ for heterogeneous nucleation of $\alpha \mathrm{Al}$. [36]

The phenomenon of Si poisoning has been observed in Al-Si alloys containing more than 3\% Si inoculated with Al-5Ti-1B grain refiner. [19-23, 30-32] Sigworth and Guzowaski [20] and Johnsson et al [21-22] showed that, with inoculation by Al-5Ti-1B, the grain size of Al-Si alloys first decreased slightly and then increased with increasing Si content with a minimum value at $\sim 3 \% \mathrm{Si}$. A number of studies subsequently confirmed the poisoning effect of Si. [2334] In addition, it was found that at a given processing temperature and a given $\mathrm{Si}$ concentration (>3\%), the grain size increases with increasing holding time of the melt prior casting. [32] Furthermore, Si poisoning has also been reported in Al-Si alloys without the addition of Al-5Ti-1B grain refiner. It was found that the grain size of un-inoculated Al-Si alloys began to increase after reaching to a minimum value at $3 \%$ Si. [26, 29-31, 34]

Overcoming Si poisoning has been a significant research topic in the past decades. The major approaches include: (i) higher addition level of hyper-stoichiometric (the stoichiometric weight ratio of Ti:B = 2.2:1) Al-Ti-B master alloys; [32-33, 37] (ii) modification of grain refiner composition, such as Al-2.2Ti-1B, Al-3Ti-3B and Al-1Ti-3B; [37-41] and (iii) development of new grain refiners based on the other alloy systems, such as Al-Ti-C, [37, 42-43] Al-Ti-B-C, [44] Al-B [37,40,45-47] and Al-Nb-B. [48-50] For instance, addition level of as high as $0.6 \%$ (typically $0.1 \%$ for a standard practice in industry) of Al-5Ti-1B grain refiner was shown to result in a fully refined structure for Al-7Si alloys. [32, 33] In addition, some newly developed alternatives, such as $\mathrm{Al}-3 \mathrm{Ti}-3 \mathrm{~B}$ and $\mathrm{Al}-1 \mathrm{Ti}-3 \mathrm{~B}$ (sub-stoichiometric), have been reported to provide a better grain refinement performance than the conventional Al-5Ti-B refiner. [37-40] Furthermore, binary Al-B system without Ti involved, Al-3B for instance, was shown to offer a better refining performance than Al-5Ti-1B. [33, 45-47] More recently, Al-2Nb-2B based grain refiner were claimed to offer good performance in grain refinement of Al-Si alloys with poisoning resistance. [48-50] Effect of trace elements on refining effectiveness of Al-Ti-B based refiner has also been investigated. It was noted that some elements, such as $\mathrm{Mg}$ and $\mathrm{Sr}$ etc., were shown to counteract Si poisoning. [32, 41, 51]

A number of hypotheses were proposed to explain the mechanism for Si poisoning, although no consensus has been reached so far. One school of thoughts is the formation of Ti-Si or Ti$\mathrm{Si}-\mathrm{Al}$ compounds on the $\mathrm{TiB}_{2}$ surface. It was postulated that formation of the silicides by interaction between $\mathrm{TiB}_{2}$ and solute $\mathrm{Si}$ made the nucleant particles less potent, [20, 21, 35, 5254] although there was little direct experimental evidence for this mechanism. For instance, formation of $\mathrm{Ti}$-Si compounds at the $\mathrm{TiB}_{2} / \alpha \mathrm{Al}$ interface was reported only in metallic glass $\left(\mathrm{Al}_{80} \mathrm{Ni}_{10} \mathrm{Cu}_{8} \mathrm{Si}_{2}\right.$ alloy containing up to $\left.0.09 \% \mathrm{Ti}\right)$, [52-54] but not in $\mathrm{Al}$ melt containing high $\mathrm{Si}$ content. Thermodynamic analysis for formation of various silicides was carried out. $[35,55]$ It was reported that, with increasing Si content, the Ti level required for $\mathrm{TiSi}_{2}$ formation is reduced. [55] In addition, based on thermodynamics and lattice matching, [35] it was suggested that, among all the possible $\mathrm{Ti}-\mathrm{Si}$ or $\mathrm{Ti}-\mathrm{Si}-\mathrm{Al}$ compounds, $\mathrm{Ti}_{5} \mathrm{Si}_{3}$ was the likely one to form on $\mathrm{TiB}_{2}$ surface causing poisoning effect. Another school of thoughts involves the increased 
growth velocity of $\alpha \mathrm{Al}$. Due to a reduced growth restriction caused by formation of titanium silicides, [56] the growth velocity of $\alpha \mathrm{Al}$ would increase. Thermodynamic calculations also showed that, with high level of Si and excess Ti in Al-Si melt, the growth restriction parameter $\mathrm{Q}$ would be greatly affected by strong exothermic interaction between the solutes $\mathrm{Si}$ and $\mathrm{Ti}$. [57] "Coincidently" at $3 \% \mathrm{Si}$, a morphological transition from globular (cellular) to dendritic for $\alpha \mathrm{Al}$ was observed. [29] It was thus suggested that highly branched dendrites, which grew more rapidly, had a smaller dendrite tip radius and were thus able to disperse solute sideways as opposed to globular tips which pushed solute ahead of the solid/liquid interface. Arguably $\mathrm{Si}$ poisoning was attributed to the increase in the growth velocity of the dendrite arms due to a decreased tip radius with increasing Si content, $[22,23,58]$ although the similar morphological transition was observed in Al-Cu alloys. [30, 59] Other hypotheses involve the change of solid/liquid interfacial energy, [29, 32, 60] solidification range [24, 30, 31] despite limited understanding, [61] and reduced peritectic temperature for the formation of a ternary aluminide (Al-Ti-Si) layer. [37]

Si poisoning has been a well-known phenomenon observed in various Al-Si alloys for decades. Although a number of explanations have been proposed, the exact cause remains elusive. In this work, based on the confirmation of Si poisoning in Al-Si binary alloys solidified at a constant cooling rate, extensive electron microscopy was carried out on the collected $\mathrm{TiB}_{2}$ particles from Al-Si melts, focusing on $\mathrm{TiB}_{2} / \alpha \mathrm{Al}$ interfaces to reveal any possible structural and chemical modification of the $\mathrm{TiB}_{2}$ particles caused by interactions between solute $\mathrm{Si}$ or impurity elements and the introduced $\mathrm{TiB}_{2}$ particles. Composition profiles of Si and relevant impurities were established at local areas across the $\mathrm{TiB}_{2} / \alpha \mathrm{Al}$ interface by high resolution STEM and high resolution Super-X EDS analysis. Based on the experimental findings of Si segregation at $\mathrm{TiB}_{2} / \alpha \mathrm{Al}$ (liquid) interface and the subsequent influence on the potency of $\mathrm{TiB}_{2}$ particles for heterogeneous nucleation of $\alpha \mathrm{Al}$, we aim to identify the operating mechanism for Si poisoning of Al-Ti-B based grain refiners, providing elucidation of experimental observations. Understanding of mechanism for the poisoning effect provides the basis for developments of effective methods and alternative grain refiners to alleviate and overcome eventually the negative poisoning effect.

\section{Experimental}

\subsection{Raw Materials}

Commercial purity aluminum (CP-Al) and Al-50Si master alloy were used in this work. Al-Si alloys containing up to $10 \% \mathrm{Si}$ were prepared using the $\mathrm{CP}-\mathrm{Al}$ and $\mathrm{Al}-50 \mathrm{Si}$ master alloy in a resistance furnace at $750^{\circ} \mathrm{C}$ with isothermal holding for an hour after melting. $\mathrm{TiB}_{2}$ particles were introduced by addition of $0.2 \%$ commercial Al-5Ti-1B grain refiner rods, supplied by LSM (Rotherham, UK). The chemical compositions and impurity levels of the materials used in this work are given in Table 1.

Table 1 Compositions (wt.\%) of materials used in this work.

\begin{tabular}{|l|l|l|l|l|l|l|l|l|l|l|l|}
\hline Alloy & $\mathrm{Si}$ & $\mathrm{Ti}$ & $\mathrm{B}$ & $\mathrm{Fe}$ & $\mathrm{V}$ & $\mathrm{Zn}$ & $\mathrm{Ni}$ & $\mathrm{Cu}$ & $\mathrm{Cr}$ & $\mathrm{Al}$ & Supplier \\
\hline
\end{tabular}




\begin{tabular}{|l|l|l|l|l|l|l|l|l|l|l|l|}
\hline CP-Al & 0.03 & 0.006 & -- & 0.08 & -- & 0.003 & 0.005 & 0.001 & 0.001 & Bal. & Norton \\
\hline $\begin{array}{l}\text { Al- } \\
50 \mathrm{Si}\end{array}$ & 49.90 & 0.02 & -- & 0.60 & -- & 0.02 & 0.01 & 0.03 & 0.01 & Bal. & $\begin{array}{l}\text { Avon } \\
\text { Metals }\end{array}$ \\
\hline $\begin{array}{l}\text { Al- } \\
\text { 5Ti-B }\end{array}$ & 0.08 & 4.8 & 0.85 & 0.09 & 0.04 & -- & -- & -- & -- & Bal. & LSM \\
\hline
\end{tabular}

\subsection{Casting and grain size assessment}

The grain size of the Al-Si alloys was assessed using the standard TP-1 test [62] which provides a consistent cooling rate of $\sim 3.5 \mathrm{~K} / \mathrm{s}$ at the central region of the transverse section 38 $\mathrm{mm}$ from the bottom of the TP-1 cast ingot. After the addition of $0.2 \%$ Al-5Ti-1B grain refiner, the Al-Si melt was holding for further $30 \mathrm{~min}$. at $750{ }^{\circ} \mathrm{C}$ and stirred in every 10 minutes, and then poured into the pre-heated TP- 1 mold $\left(350^{\circ} \mathrm{C}\right)$ which was then cooled by water spray with a flow rate of $3.8 \mathrm{l} / \mathrm{min}$. For comparison, TP- 1 tests were also conducted for CP-Al with and without inoculation with the commercial Al-5Ti-1B grain refiner.

Examination of grain structure and quantification of grain size of the solidified TP-1 samples were carried out at the transverse section $38 \mathrm{~mm}$ from the base, and the longitudinal section of the lower part of the TP-1 ingots. The specimens for the quantitative metallography were prepared following the standard procedures, subjected to a final polishing before anodizing using Barker's reagent ( $5 \mathrm{ml} \mathrm{HBF} 4+200 \mathrm{ml}$ distilled water). A Zeiss optical microscope fitted with the Axio Vision 4.3 image analysis system was used for the grain size measurement. For each of the measurement by the mean linear intercept technique, the average of at least 500 grains from areas covering the whole transverse section of the TP-1 ingot was taken for the quantification of the grain size under the given casting conditions.

\subsection{SEM and high resolution TEM/STEM}

In order to facilitate examinations of $\mathrm{TiB}_{2}$ particles and their interfaces with $\alpha \mathrm{Al}$ by electron microscopy, a pressurized melt filtration technique was used to collect the $\mathrm{TiB}_{2}$ particles in the $\mathrm{Al}-\mathrm{Si}$ melts inoculated with $\mathrm{Al}-5 \mathrm{Ti}-1 \mathrm{~B}$ grain refiner. In this process, the prepared $\mathrm{CP}-\mathrm{Al}$ or $\mathrm{Al}-$ Si alloy melt containing $\mathrm{TiB}_{2}$ particles was transferred into the crucible in the pressure chamber of the melt filtration unit. Argon was introduced to force the melt to flow through a porous ceramic filter attached to the bottom of the crucible. $\mathrm{TiB}_{2}$ particles were thus collected immediate above the filter. The solidified material above the filter, which contained the locally concentrated $\mathrm{TiB}_{2}$ particles, was subjected to sampling. A detailed description of melt filtration for collection of particles can be found elsewhere. [63, 64]

The collected $\mathrm{TiB}_{2}$ particles, their surface and interface with $\alpha \mathrm{Al}$ in particular, were examined. Scanning electron microscopy (SEM) was performed using a Carl Zeiss Crossbeam 340 microscope equipped with energy dispersive x-ray spectroscopy (EDS). Thin foil specimens for transmission electron microscopy (TEM) and scanning transmission electron microscopy (STEM) were prepared from $3 \mathrm{~mm}$ diameter discs sliced from the filtered residue material. The discs were manually ground to a thickness less than $60 \mu \mathrm{m}$ before further thinning by argon ion beam milling using a Gatan precision ion polishing system (PIPS) under a voltage of 1.0-5.0 
$\mathrm{kV}$ and an incident beam angle of $3-5^{\circ}$. High resolution TEM examination was conducted on a JEOL 2100F microscope operated with an accelerating voltage of $200 \mathrm{kV}$. Atomic resolution STEM with Z contrast high-angle annular dark filed (HAADF) imaging was carried out on an aberration (Cs)-corrected FEI Titan 80-200 instrument equipped with Super-X energy dispersive $\mathrm{x}$-ray spectroscopy (Super-X EDS) system, operated with an accelerating voltage of $200 \mathrm{kV}$. High resolution elemental mapping by STEM/Super-X EDS was conducted to obtain compositional profiles across $\mathrm{TiB}_{2} / \alpha \mathrm{Al}$ interface.

\section{Results}

\subsection{Si poisoning of Al-5Ti-1B grain refiner}

Figure 1 shows the typical macrostructures of CP-Al, Al-2.0Si and Al-8.4Si alloys solidified under the TP-1 test conditions. As expected, the addition of $0.2 \%$ Al-5Ti-1B grain refiner resulted in a significant grain refinement of $\mathrm{CP}-\mathrm{Al}$, transforming the coarse columnar grain structure (Figures 1a and 1b) into a fine and fully equiaxed one (Figures 1c and 1d). Similarly, a considerably refined and fully equiaxed grain structure was obtained for Al-2.0Si alloy inoculated with the grain refiner, as shown in Figures 1e and 1f. However, Al-8.4Si alloy inoculated with the same amount of the grain refiner showed a coarse and equiaxed grain structure (Figures $1 \mathrm{~g}$ and $1 \mathrm{~h}$ ). The optical micrographs in Figure 2 show the microstructures of $\mathrm{Al}-2.0 \mathrm{Si}$ and $\mathrm{Al}-8.4 \mathrm{Si}$ alloys inoculated with the Al-5Ti-1B grain refiner. The average grain size of the primary $\alpha \mathrm{Al}$ phase for Al-2.0Si alloy is $195 \pm 22 \mu \mathrm{m}$, being comparable to $202 \pm 26$ $\mu \mathrm{m}$ for the refined CP-Al. However, the grain size is $686 \pm 73 \mu \mathrm{m}$ for the inoculated Al-8.4Si alloy, which is considerably larger than that for the inoculated Al-2.0Si alloy. In addition, there is also clear difference in grain morphology between Al-2.0Si and Al-8.4Si alloys. The primary $\alpha \mathrm{Al}$ has a typical rosette morphology for the inoculated Al-2.0Si alloy (Figure 2c), but a welldeveloped dendritic morphology for the inoculated Al-8.4Si alloy (Figure 2d).
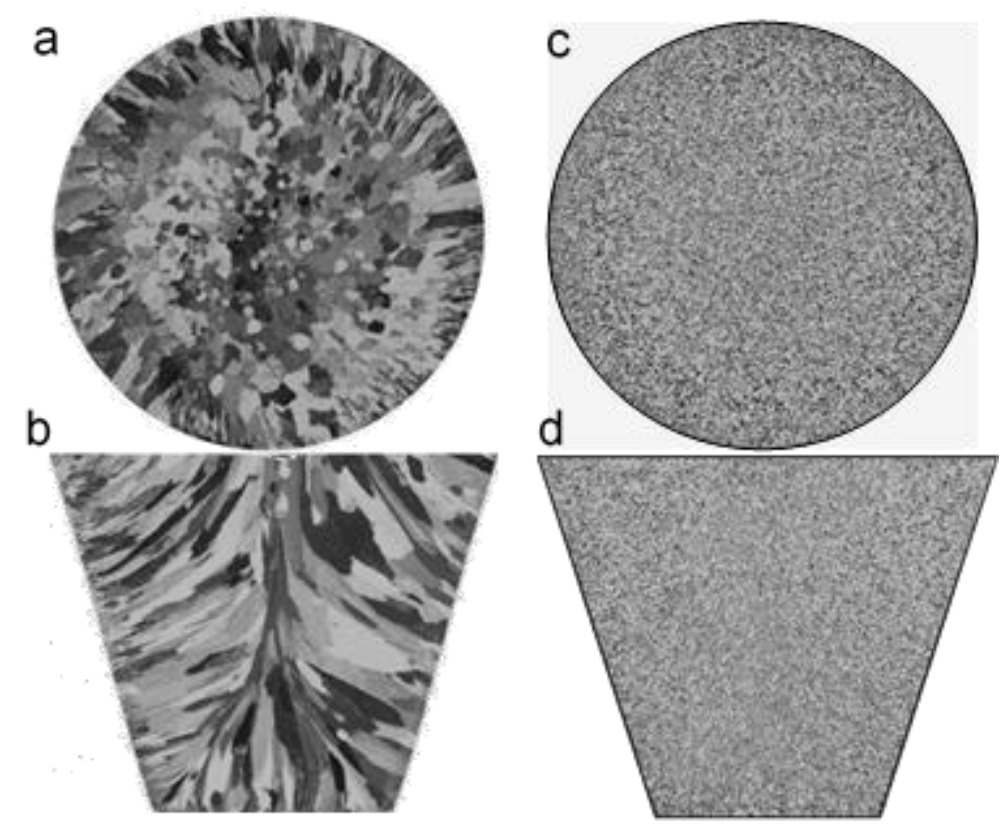

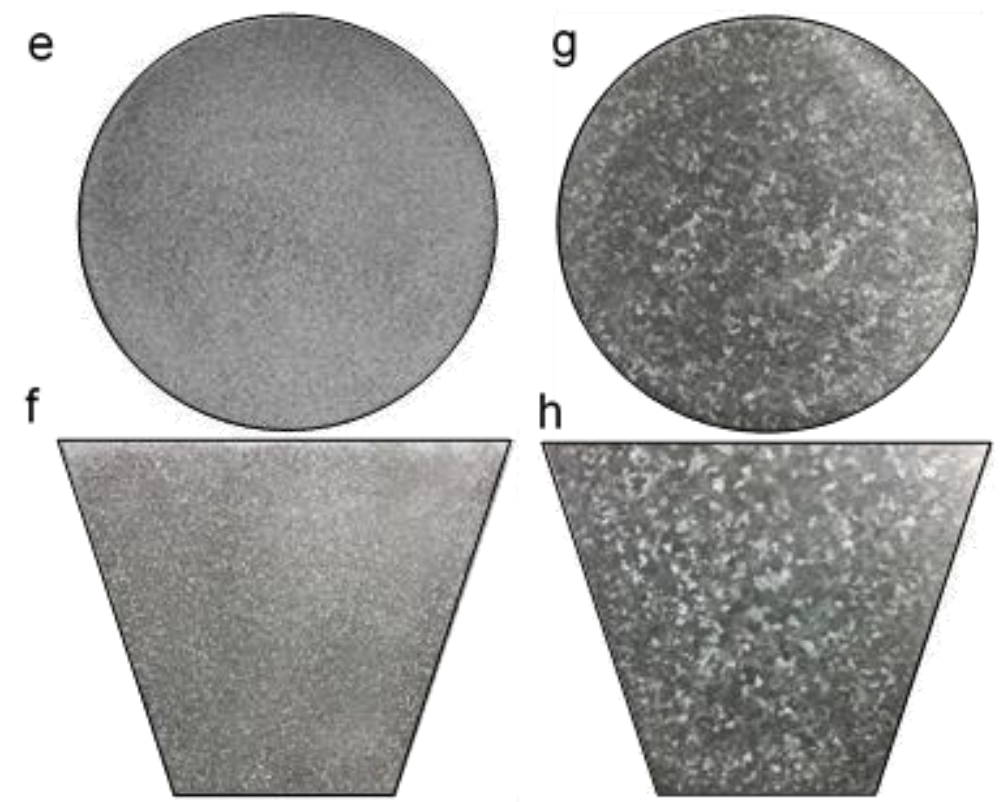

Fig. 1 Macrographs showing grain structures of TP-1 test samples on (a, c, e, g) transverse and (b, d, f, h) longitudinal sections of (a, b) CP-Al with no addition of grain refiner, (c, d) CP-Al, (e, f) Al-2.0Si and $(\mathrm{g}, \mathrm{h}) \mathrm{Al}-8.4 \mathrm{Si}$ alloys with addition of $0.2 \mathrm{wt} \%$ commercial Al-5Ti-1B grain refiner.
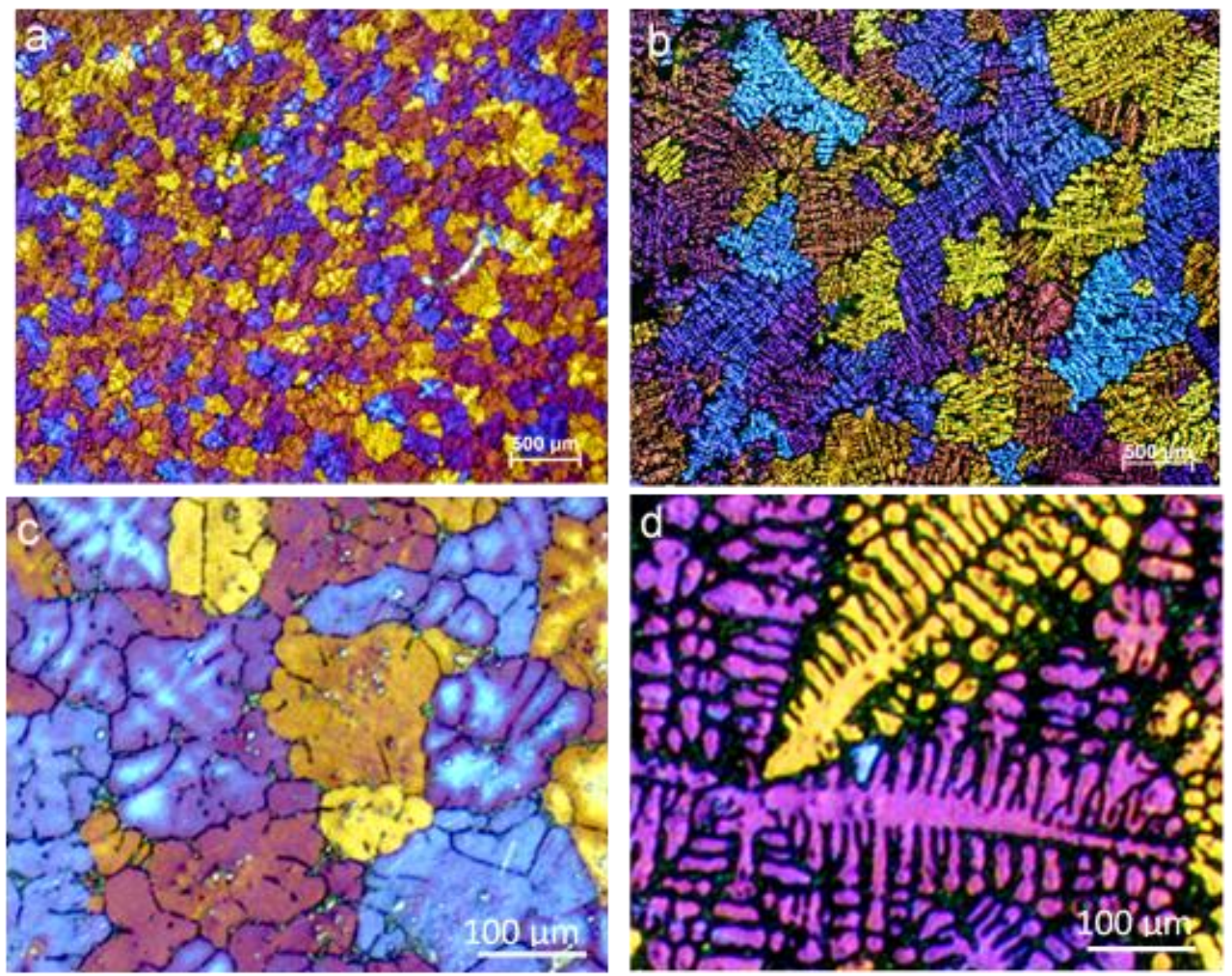

Fig. 2 Optical micrographs showing ( $a, b)$ general view of grain structures of TP-1 test samples of (a) Al-2.0Si and (b) Al-8.4Si alloy inoculated with $0.2 \mathrm{wt} \%$ Al-5Ti-1B, and (c, d) morphological transition from cellular to dendritic for the primary $\alpha \mathrm{Al}$ with Si concentration increasing from (c) $2.0 \mathrm{wt} \%$ to (d) $8.4 \mathrm{wt} \%$. The average grain size of $\alpha \mathrm{Al}$ is measured to be $195 \pm 22 \mu \mathrm{m}$ and $686 \pm 73 \mu \mathrm{m}$ for Al-2.0Si and Al-8.4Si, respectively. 


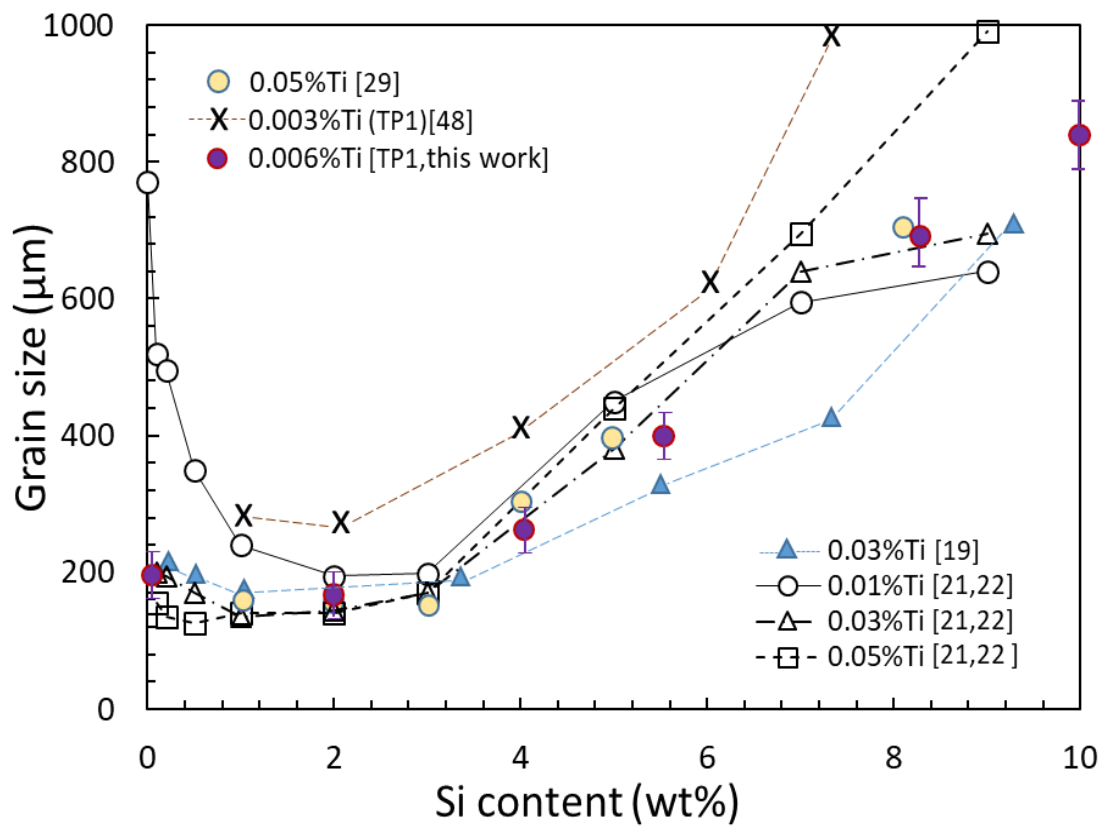

Fig. 3 Experimentally measured grain size of the primary $\alpha \mathrm{Al}$ of hypoeutectic Al-Si alloys inoculated with Al-5Ti-1B grain refiner as a function of Si concentration, together with the representative data found in the literature.

The experimentally measured grain size is plotted in Figure 3 as a function of Si concentration, being compared with the representative experimental data found in the literature. In agreement with previous studies, the present work confirms the variation in grain size of Al-Si alloys with changing Si content, although the absolute values of grain size vary, probably due to the differences in the addition level of grain refiner, alloy composition, impurity level and solidification conditions in the different studies. All the experimental observations show in general that, when inoculated with Al-5Ti-1B grain refiners, grain size of hypoeutectic Al-Si alloys decreases slightly until $\sim 3 \% \mathrm{Si}$ and then increases with further increase of Si content.

\section{2 $\mathrm{TiB}_{2}$ particles added to Al-Si alloy melts}

$\mathrm{TiB}_{2}$ particles collected from the Al-Si alloy melt were subjected to extensive examinations by various microscopic techniques. The reference point for this study is the original state of the $\mathrm{TiB}_{2}$ particles from the commercial grain refiner. Such $\mathrm{TiB}_{2}$ particles are potent substrates for heterogeneous nucleation of $\alpha \mathrm{Al}$ due to the presence of $\mathrm{Al}_{3} \mathrm{Ti} 2 \mathrm{DC}$ layer on their $\left(\begin{array}{llll}0 & 0 & 0 & 1\end{array}\right)$ surface. $[8,36]$ There exists a well-defined orientation relationship (OR) between $\mathrm{TiB}_{2}$ and $\alpha \mathrm{Al}$ : $[8,36]$

$$
\left(\begin{array}{llll}
0 & 0 & 0 & 1
\end{array}\right)\left[\begin{array}{llll}
1 & 1 & -2 & 0
\end{array}\right] \mathrm{TiB}_{2} / /\left(\begin{array}{lll}
1 & 1 & 1
\end{array}\right)\left[\begin{array}{lll}
0 & -1 & 1
\end{array}\right] \alpha \mathrm{Al}
$$

(OR1)

which serves as hard evidence for the nucleation of $\alpha \mathrm{Al}$ on $\mathrm{TiB}_{2}$ substrate.

Figure $4 \mathrm{a}$ shows the typical hexagonal morphology of the $\mathrm{TiB}_{2}$ particles collected from the Al8.4Si alloy melt inoculated with $0.2 \%$ Al-5Ti-1B. Compared with the original $\mathrm{TiB}_{2}$ particles from the commercial grain refiner, [65] there was no visible change in morphology and size 
after they were added to the melt and isothermally hold at $750^{\circ} \mathrm{C}$. Figure $4 \mathrm{~b}$ is a TEM bright field image showing the sharp $\mathrm{TiB}_{2} / \mathrm{Si}$ interfaces at a higher magnification. Extensive high resolution TEM examination of multiple $\mathrm{TiB}_{2}$ particles focusing on both $\mathrm{TiB}_{2} / \alpha \mathrm{Al}$ and $\mathrm{TiB}_{2} / \mathrm{Si}$ interfaces revealed no evidence for the formation of any $3 \mathrm{D}$ bulk phase at the interfaces. Examples are given in Figures $4 \mathrm{c}$ and $4 \mathrm{~d}$, where sharp and smooth $\mathrm{TiB}_{2} / \alpha \mathrm{Al}$ (Figure $4 \mathrm{c}$ ) and $\mathrm{TiB}_{2} / \mathrm{Si}$ (Figure 4d) interfaces are evident at atomic scale.
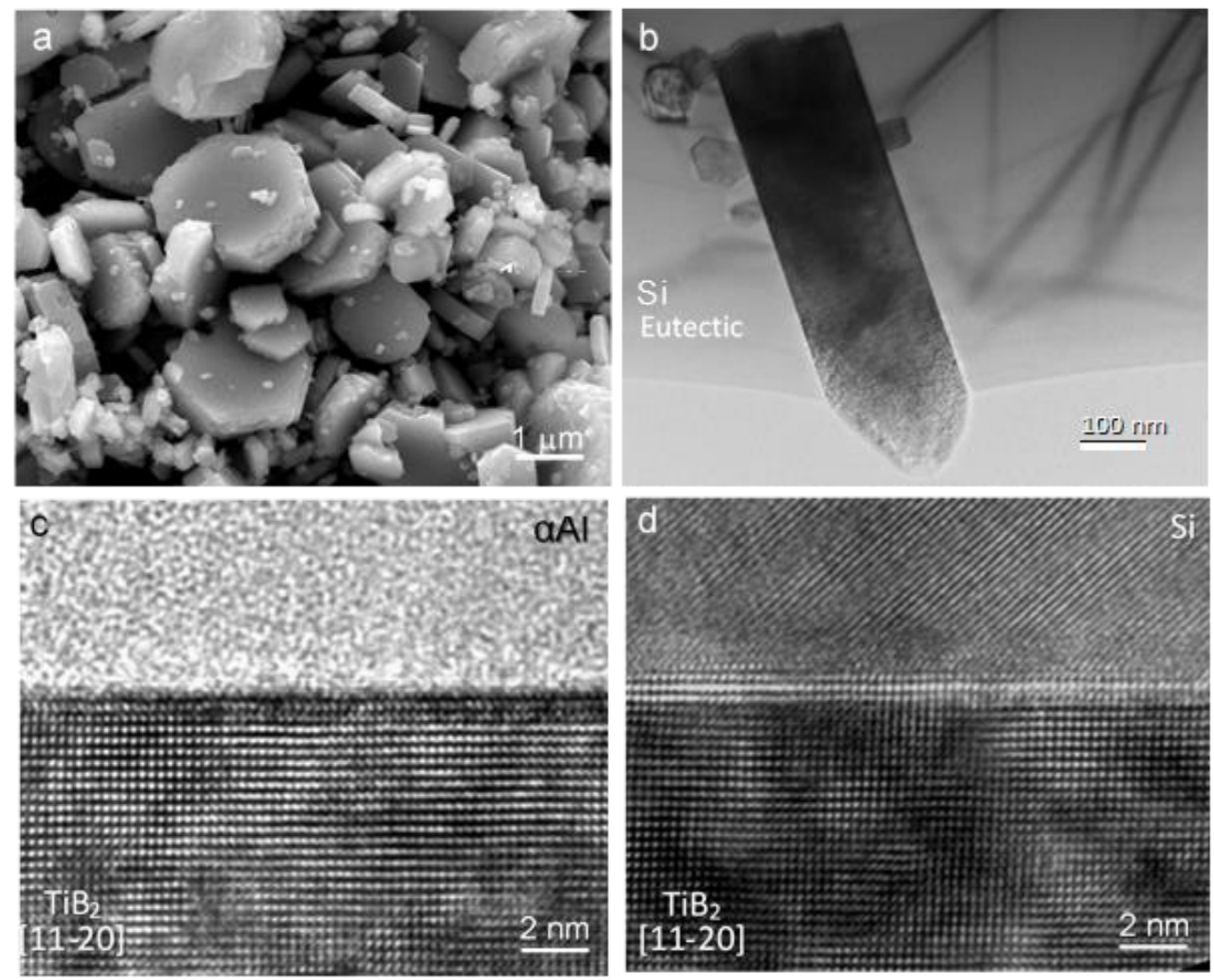

Fig. 4 (a) SEM and (b) TEM bright field image showing the morphology of $\mathrm{TiB}_{2}$ particles collected from Al-8.4Si alloy melt inoculated with $0.2 \mathrm{wt} \%$ Al-5Ti-1B grain refiner, indicating the typical hexagonal shape of $\mathrm{TiB}_{2}$ and its sharp surface; and (c, d) high resolution TEM images showing sharp and smooth (c) $\mathrm{TiB}_{2} / \alpha \mathrm{Al}$ and (d) $\mathrm{TiB}_{2} / \mathrm{Si}$ (eutectic) interfaces at atomic scale.

TEM/STEM examinations showed that the majority of $\mathrm{TiB}_{2}$ particles in $\mathrm{Al}-2.0 \mathrm{Si}$ and $\mathrm{Al}-8.4 \mathrm{Si}$ alloys were not in any defined OR with the adjacent $\alpha \mathrm{Al}$, indicating that the majority of the added $\mathrm{TiB}_{2}$ particles did not participate in grain initiation of $\alpha \mathrm{Al}$ during solidification. This is consistent with the conclusion derived from the free growth model that only less than $1 \%$ of the added $\mathrm{TiB}_{2}$ particles are active for grain initiation. [65] TEM/STEM examination of multiple $\mathrm{TiB}_{2}$ particles showed that the well-defined OR1 between $\mathrm{TiB}_{2}$ and $\alpha \mathrm{Al}$ was readily observed in the Al-2.0Si sample, as shown in Figures 5a and 5b. Occasionally, OR1 is not followed, e.g., $\left\{\begin{array}{lll}1 & 1 & 1\end{array}\right\}$ planes of $\alpha \mathrm{Al}$ being a few degrees away from being parallel to $\left\{\begin{array}{llll}0 & 0 & 0 & 1\end{array}\right\}$ planes of $\mathrm{TiB}_{2}$, although [ $\left.\begin{array}{llll}1 & 1 & -2 & 0\end{array}\right] \mathrm{TiB}_{2}$ and $\left[\begin{array}{lll}0 & -1 & 1\end{array}\right] \alpha \mathrm{Al}$ zone directions remain to be parallel to each other. As shown in Figures $5 \mathrm{c}$ and $5 \mathrm{~d}$, it is found by careful measurement through the fast Fourier 

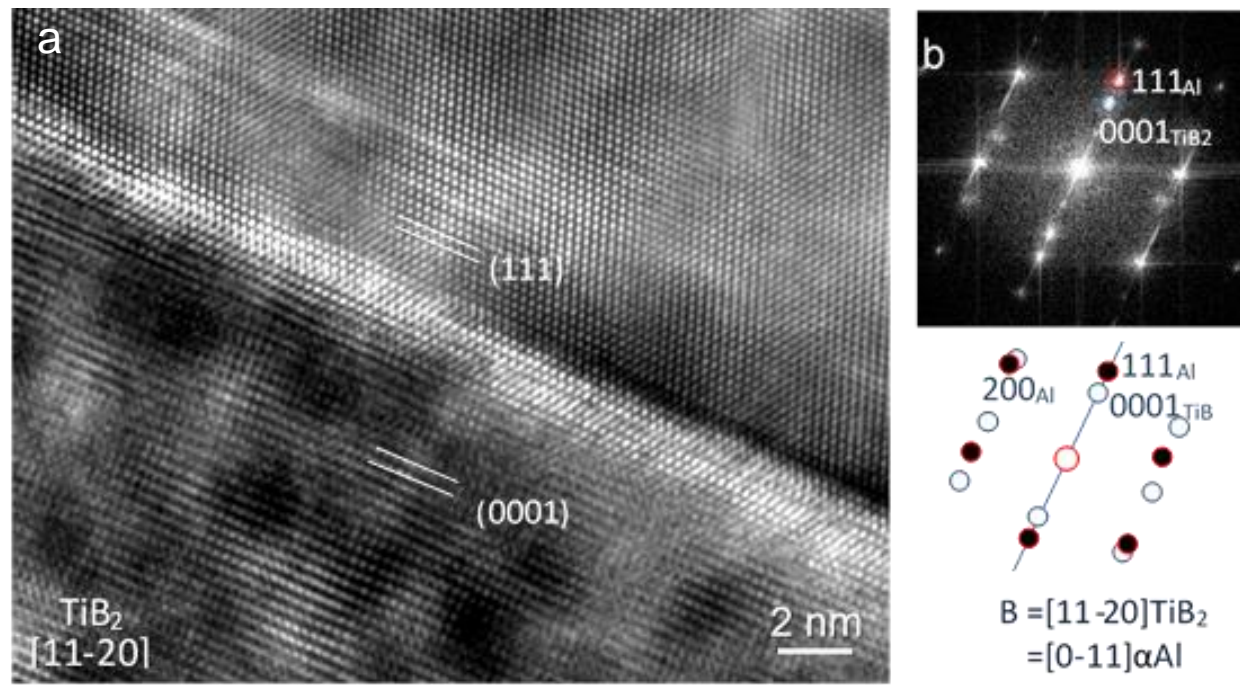

$\mathrm{B}=[11-20] \mathrm{TiB}_{2}$

$=[0-11] \alpha A \mid$
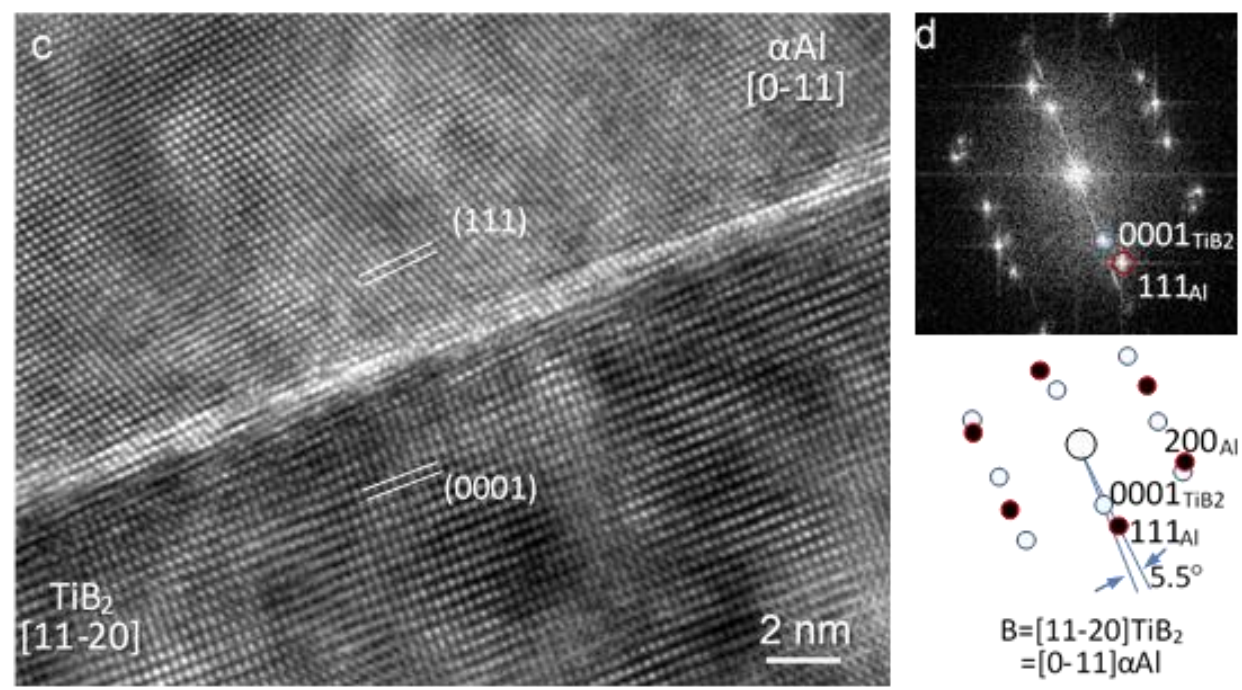

Fig. 5 (a, c) High resolution TEM images showing $\mathrm{TiB}_{2} / \alpha \mathrm{Al}$ interfaces in Al-2.0Si alloy sample where the $\mathrm{TiB}_{2}$ particle and $\alpha \mathrm{Al}$ are viewed along [ $\left[\begin{array}{llll}1 & 1 & -2 & 0\end{array}\right] \mathrm{TiB}_{2}$ and $\left[\begin{array}{lll}0 & -1 & 1\end{array}\right] \alpha \mathrm{Al}$ zone directions respectively; and $(b, d)$ the corresponding fast Fourier transformation (FFT) patterns and their index showing that $\left(\begin{array}{lll}1 & 1 & 1\end{array}\right) \alpha \mathrm{Al}$ plane has a 5.5 degrees angle from $\left(\begin{array}{llll}0 & 0 & 0 & 1\end{array}\right) \mathrm{TiB}_{2}$ plane in $(\mathrm{c}, \mathrm{d})$.

transformation (FFT) patterns that $\left(\begin{array}{lll}1 & 1 & 1\end{array}\right) \alpha \mathrm{Al}$ plane is $\sim 5.5^{\circ}$ away from being parallel to $\left(\begin{array}{lll}0 & 0 & 0\end{array}\right.$

273 1) $\mathrm{TiB}_{2}$ plane. This gives:

$$
\left(\begin{array}{llll}
0 & 0 & 0 & 1
\end{array}\right) \mathrm{TiB}_{2} \sim 5.5^{\circ}\left(\begin{array}{lll}
1 & 1 & 1
\end{array}\right) \alpha \mathrm{Al} \text {, and }\left[\begin{array}{llll}
1 & 1 & -2 & 0
\end{array}\right] \mathrm{TiB}_{2} / /\left[\begin{array}{lll}
0 & -1 & 1
\end{array}\right] \alpha \mathrm{Al} \text {. }
$$

(OR2)

OR2 is actually equivalent to:

$$
\left(\begin{array}{llll}
0 & 0 & 0 & 1
\end{array}\right)\left[\begin{array}{llll}
1 & 1 & -2 & 0
\end{array}\right] \mathrm{TiB}_{2} / /\left(\begin{array}{lll}
5 & 5 & 4
\end{array}\right)\left[\begin{array}{lll}
0 & -1 & 1
\end{array}\right] \alpha \mathrm{Al}
$$

277 In this case, the actual crystal plane of $\alpha \mathrm{Al}$ which is parallel to $\left(\begin{array}{llll}0 & 0 & 0 & 1\end{array}\right) \mathrm{TiB}_{2}$ is $\left(\begin{array}{lll}5 & 5 & 4\end{array}\right)$, a 278 relatively high index crystal plane of $\alpha \mathrm{Al}$.

279 However, TEM/STEM examinations of the $\mathrm{TiB}_{2}$ particles collected from Al-8.4Si alloy melt 280 inoculated with $0.2 \% \mathrm{Al}-5 \mathrm{Ti}-1 \mathrm{~B}$ grain refiner failed to find any well-defined OR between $\mathrm{TiB}_{2}$ 281 and $\alpha \mathrm{Al}$, although as many as $80 \mathrm{TiB}_{2}$ particles in total were examined in multiple thin foil 
TEM specimens. $\mathrm{TiB}_{2}$ and adjacent $\mathrm{Al}$ were occasionally found to be in some sort of orientations considerably deviated from OR1. For example, Figure 6 shows that, in one occasion, ( $\left.\begin{array}{lll}1 & 1 & 1\end{array}\right) \alpha \mathrm{Al}$ plane is far away from being paralleled to $\left(\begin{array}{llll}0 & 0 & 0 & 1\end{array}\right) \mathrm{TiB}_{2}$, and $\left[\begin{array}{lll}1 & 1 & 0\end{array}\right] \alpha \mathrm{Al}$ zone is not parallel to [ [ $11-2 \quad 0] \mathrm{TiB}_{2}$ zone either. Instead, [ $1-1-2$-2 $\alpha \mathrm{Al}$ direction is parallel to

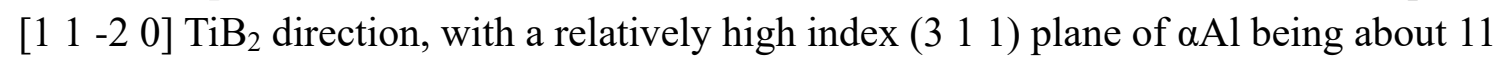
degrees away from being parallel to $\left(\begin{array}{llll}0 & 0 & 0 & 1\end{array}\right)$ surface of $\mathrm{TiB}_{2}$. Obviously this does not give a defined OR.
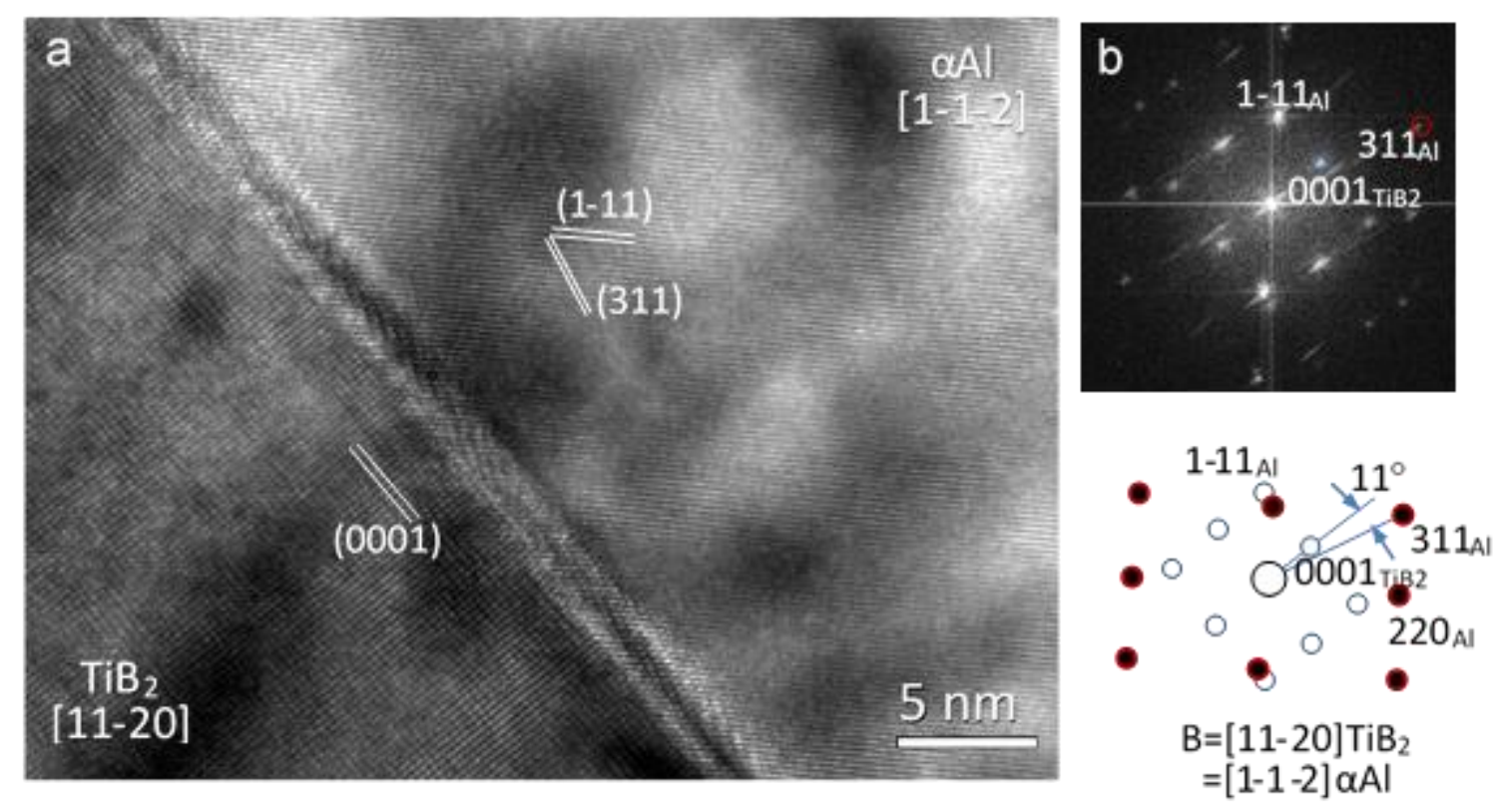

Fig. 6 (a) High resolution TEM image showing $\mathrm{TiB}_{2} / \alpha \mathrm{Al}$ interface of a $\mathrm{TiB}_{2}$ particle in $\mathrm{Al}-8.4 \mathrm{Si}$

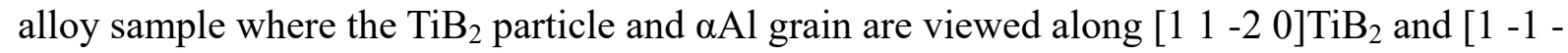
2] $\alpha \mathrm{Al}$ zone directions, respectively, and (b) the corresponding fast Fourier transformation (FFT) pattern and its index.

Figures $7 \mathrm{a}$ and $7 \mathrm{c}$ are the high resolution STEM Z-contrast HAADF images showing the $\mathrm{TiB}_{2} / \alpha \mathrm{Al}$ interface of $\mathrm{a} \mathrm{TiB}_{2}$ particle in Al-8.4Si alloy, which suggest that there exists no bulk phase at the interface, verifying the above result from traditional high resolution TEM in Figure 4. Again, atomically sharp and smooth $\mathrm{TiB}_{2} / \alpha \mathrm{Al}$ interfaces were observed. In comparison with the $\mathrm{TiB}_{2}$ in $\mathrm{CP}-\mathrm{Al}$ sample where the $\mathrm{Al}_{3} \mathrm{Ti} 2 \mathrm{DC}$ atomic layer is reserved (Figures $7 \mathrm{~b}$ and $7 \mathrm{~d}$ ), [8] it is found that the pre-existing $\mathrm{Al}_{3} \mathrm{Ti} 2 \mathrm{DC}$ layer is missing on the $\left(\begin{array}{llll}0 & 0 & 0 & 1\end{array}\right) \mathrm{TiB}_{2}$ surface for the $\mathrm{TiB}_{2}$ particle collected from the Al-8.4Si sample (Figures $7 \mathrm{a}$ and $7 \mathrm{c}$ ). High resolution STEM examination of multiple $\mathrm{TiB}_{2}$ particles collected from the Al-8.4Si melt confirmed consistently the disappearance of $\mathrm{Al}_{3} \mathrm{Ti} 2 \mathrm{DC}$ layer from $\mathrm{TiB}_{2}$ surface.

However, a different situation was revealed for the $\mathrm{TiB}_{2}$ particles collected from $\mathrm{Al}-2.0 \mathrm{Si}$ melt. Figure $8 \mathrm{a}$ is the high resolution STEM HAADF image across $\mathrm{TiB}_{2} / \alpha \mathrm{Al}$ interface with the $\mathrm{TiB}_{2}$

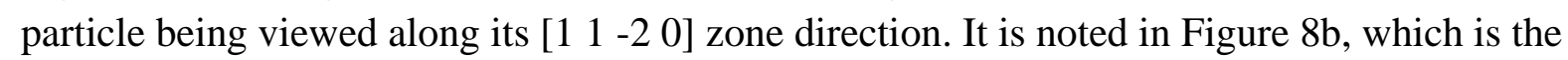
enlargement of the rectangular region marked in Fig 8a, that the $\mathrm{Al}_{3} \mathrm{Ti} 2 \mathrm{DC}$ remains on the left hand side of the $\left(\begin{array}{llll}0 & 0 & 0 & 1\end{array}\right) \mathrm{TiB}_{2}$ surface but is absent on the right hand side. As shown at higher magnification in Figure $8 \mathrm{~b}$, the brightness of the atomic columns of the $\mathrm{Al}_{3} \mathrm{Ti} 2 \mathrm{DC}$ layer in the 

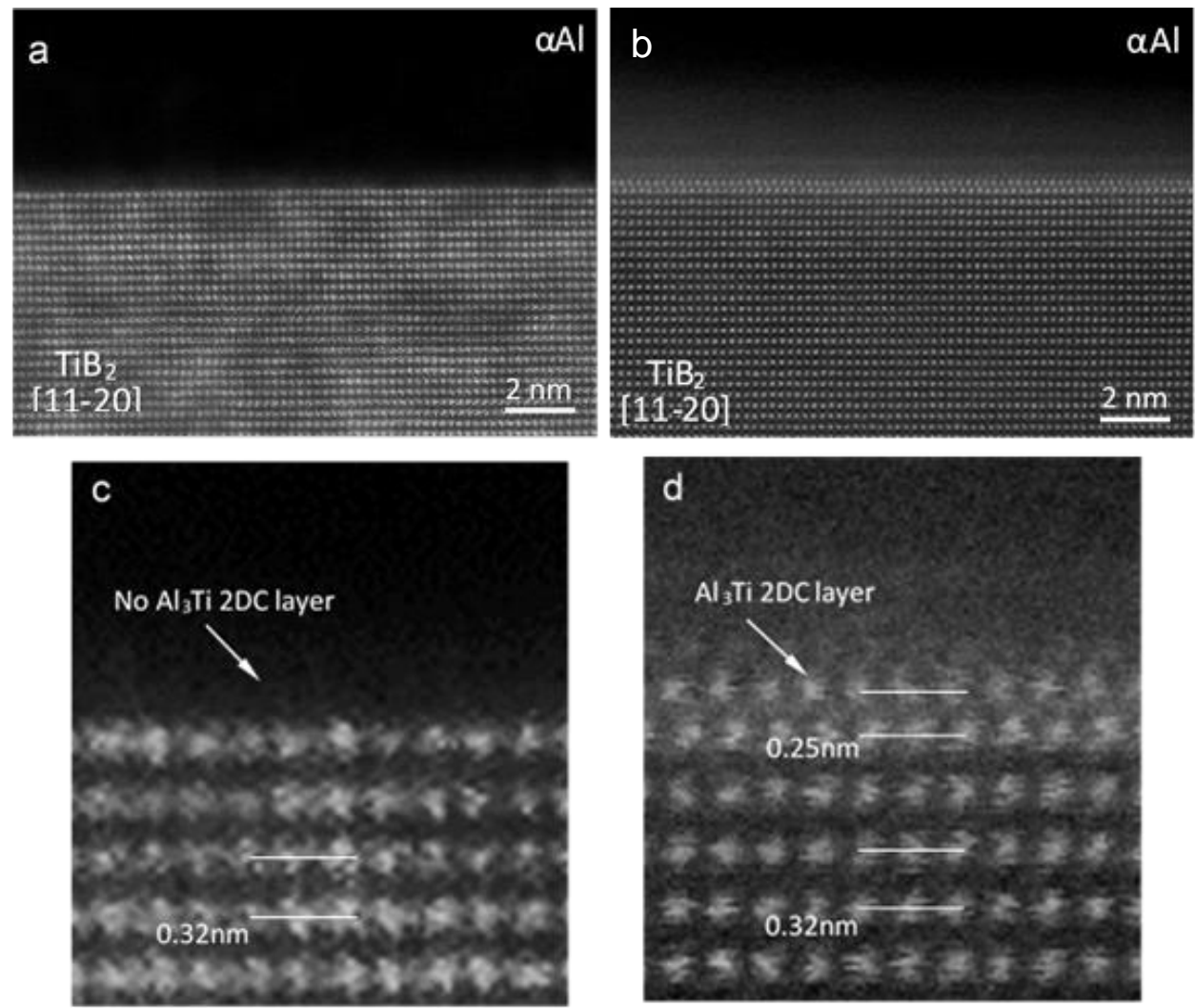

Fig. 7 High resolution STEM Z-contrast HAADF images of $\mathrm{TiB}_{2} / \alpha \mathrm{Al}$ interface showing $\left(\begin{array}{lll}0 & 0 & 0\end{array}\right.$

313 1) surface of $\mathrm{TiB}_{2}$ viewed along [ $\left.\begin{array}{llll}1 & 1 & -2 & 0\end{array}\right] \mathrm{TiB}_{2}$ zone direction in (a, c) Al-8.4Si alloy and (b, d)

$314 \mathrm{CP}-\mathrm{Al}$. It is clear from (c, d) the HAADF images at higher magnifications that the $\mathrm{Al}_{3} \mathrm{Ti} 2 \mathrm{DC}$

315 layer $[8,36]$ is missing on the $\left(\begin{array}{llll}0 & 0 & 0 & 1\end{array}\right) \mathrm{TiB}_{2}$ surface in (c) Al-8.4Si sample but present in (d)

316 CP-Al sample.

STEM HAADF image is seen to start weakening at the position marked by the arrow and the atomic columns disappear completely towards the right hand side of the interface. This suggests that it is of significance that the $\mathrm{Al}_{3} \mathrm{Ti}$ 2DC layer is not stable and tends to dissolve in the Al-Si melt. Figure 8 shows the on-going dissolution process of the 2DC layer, which occurs gradually after the $\mathrm{TiB}_{2}$ particles were added to the Al-Si melt and holding at the processing temperature. In this work, $\mathrm{Al}_{3} \mathrm{Ti} 2 \mathrm{DC}$, which was formed on the surface of $\mathrm{TiB}_{2}$ particles during production process of the commercial Al-5Ti-1B grain refiner, [8] was readily observed to remain on the surface of $\mathrm{TiB}_{2}$ particles collected from the Al-2.0Si melt. This is in contrast to the situation in $\mathrm{Al}-8.4 \mathrm{Si}$ sample where the $\mathrm{Al}_{3} \mathrm{Ti}$ 2DC layer was not at all observed, although multiple number of $\mathrm{TiB}_{2}$ particles have been examined by high resolution STEM. That the possibility to observe the remaining $\mathrm{Al}_{3} \mathrm{Ti} 2 \mathrm{DC}$ layer is considerably smaller in $\mathrm{Al}-8.4 \mathrm{Si}$ sample than that in Al-2.0Si indicates a faster dissolution rate for the 2DC layer in Al-Si melt with a higher Si content.

Apparently Si concentration plays an important role in determining the dissolution kinetics of the $\mathrm{Al}_{3} \mathrm{Ti} 2 \mathrm{DC}$ layer. It is therefore essential to study the chemical profiles across $\mathrm{TiB}_{2} / \alpha \mathrm{Al}$ 

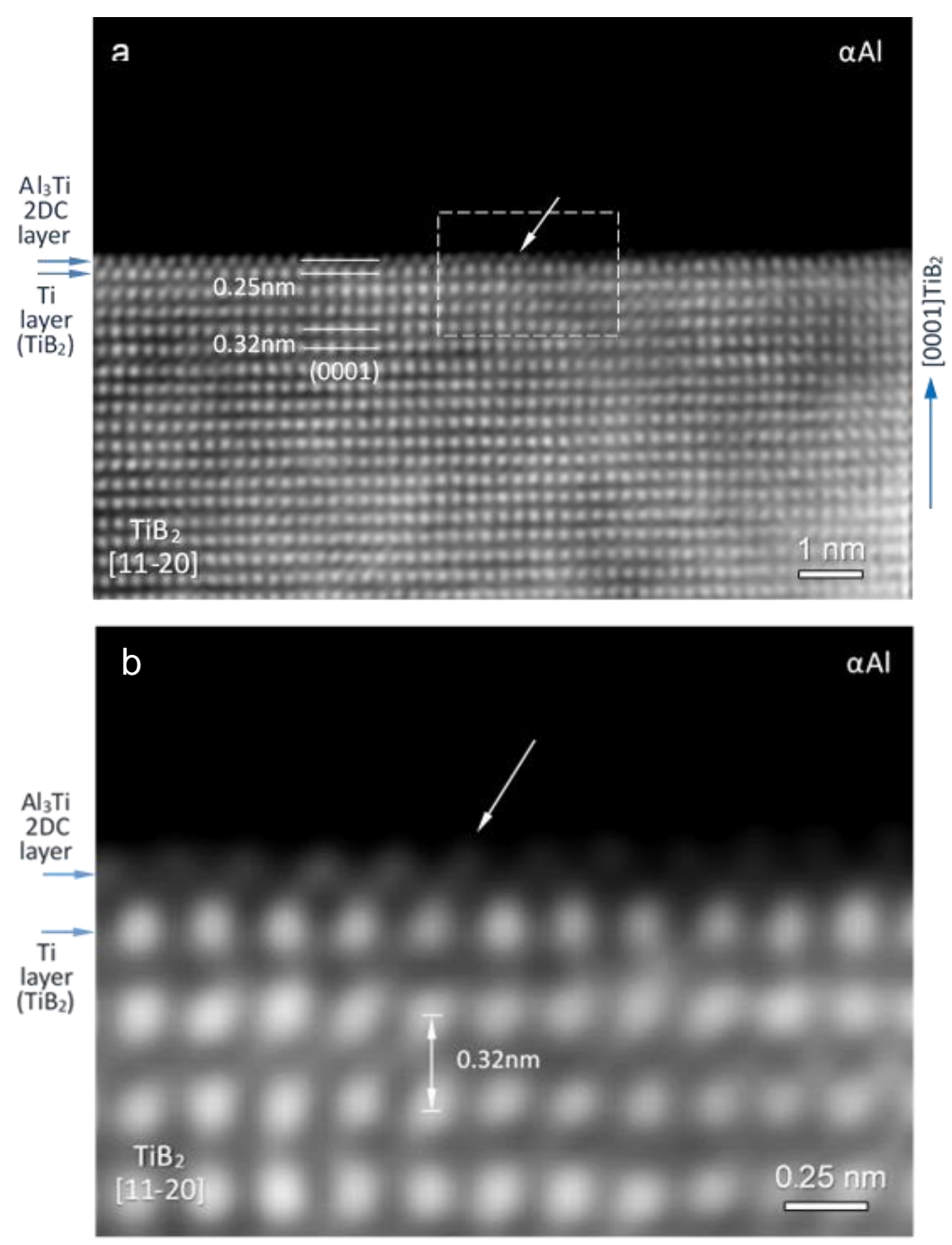

Fig. 8 High resolution STEM HAADF images across $\mathrm{TiB}_{2} / \alpha \mathrm{Al}$ interface viewed along [1 1 - 1 -2 0 ] $337 \mathrm{TiB}_{2}$ zone direction showing (a) on-going dissolution (starting at the point marked by the arrow) of $\mathrm{Al}_{3} \mathrm{Ti}$ 2DC layer on $\left(\begin{array}{llll}0 & 0 & 0 & 1\end{array}\right)$ surface of $\mathrm{TiB}_{2}$ particle collected from Al-2.0Si alloy melt, and (b) enlargement of the marked rectangular region in (a).

interface. Figure 9 presents the EDS results obtained from Al-8.4Si sample. The STEM HAADF image in Figure 9a shows the $\mathrm{TiB}_{2} / \alpha \mathrm{Al}$ interface with no $\mathrm{Al}_{3} \mathrm{Ti}$ 2DC layer covering the $\mathrm{TiB}_{2}$ surface, and the corresponding Super-X EDS spectrum in Figure $9 \mathrm{~b}$ taken from the local interface region marked in Figure 9a shows a major peak at energy $1.74 \mathrm{keV}$, i.e., the characteristic $\mathrm{K}_{\alpha}$ peak of $\mathrm{Si}$. More evidence of $\mathrm{Si}$ segregation at the $\mathrm{TiB}_{2} / \alpha \mathrm{Al}$ interface is provided by the elemental mapping of Si (Figure 9c), accompanied by those of $\mathrm{Ti}, \mathrm{Al}$ and $\mathrm{Fe}$, one of the main impurities in CP-Al (Table 1), as shown in Figures 9d-9f, respectively. It should be pointed out that $\mathrm{Si}$ segregation at $\mathrm{TiB}_{2} / \alpha \mathrm{Al}$ interface is hardly visible in terms of the brightness contrast in HAADF image due to the small difference of atomic number of Si (14) from that of $\mathrm{Al}$ (13). The EDS mapping did not suggest segregation of $\mathrm{Fe}$ at $\left(\begin{array}{llll}0 & 0 & 0 & 1\end{array}\right) \mathrm{TiB}_{2} / \alpha \mathrm{Al}$ interface (Figure 9f). Further SuperX EDS analysis of other Al-Si alloys revealed that Si segregation at the $\mathrm{TiB}_{2} / \alpha \mathrm{Al}$ interface is common to all the Al-Si alloys. The elemental mapping in Figure 10, where the $\mathrm{Al}_{3} \mathrm{Ti}$ 2DC layer was survived partially on the left-hand side of $\left(\begin{array}{llll}0 & 0 & 0 & 1\end{array}\right)$ 
$\mathrm{TiB}_{2}$ surface found in $\mathrm{a} \mathrm{TiB}_{2}$ particle collected from $\mathrm{Al}-2.0 \mathrm{Si}$ melt, indicates a similar $\mathrm{Si}$ segregation (Figure 10b) at the interface with and without the $\mathrm{Al}_{3} \mathrm{Ti} 2 \mathrm{DC}$.

Besides at $\left\{\begin{array}{llll}0 & 0 & 0 & 1\end{array}\right\} \mathrm{TiB}_{2} / \alpha \mathrm{Al}$ interface, $\mathrm{Si}$ was found to segregate also to $\left\{\begin{array}{lllll}1 & 0 & -1 & 0\end{array}\right\} \mathrm{TiB}_{2} / \alpha \mathrm{Al}$ interfaces, as shown by the EDS mapping in Figure 11. As a result, the $\mathrm{TiB}_{2}$ particles added to $\mathrm{Al}-\mathrm{Si}$ melt are actually coated by a Si-enriched layer of Al-Si melt where the Si concentration is higher than that in the bulk melt away from the $\mathrm{TiB}_{2} / \alpha \mathrm{Al}$ interface.
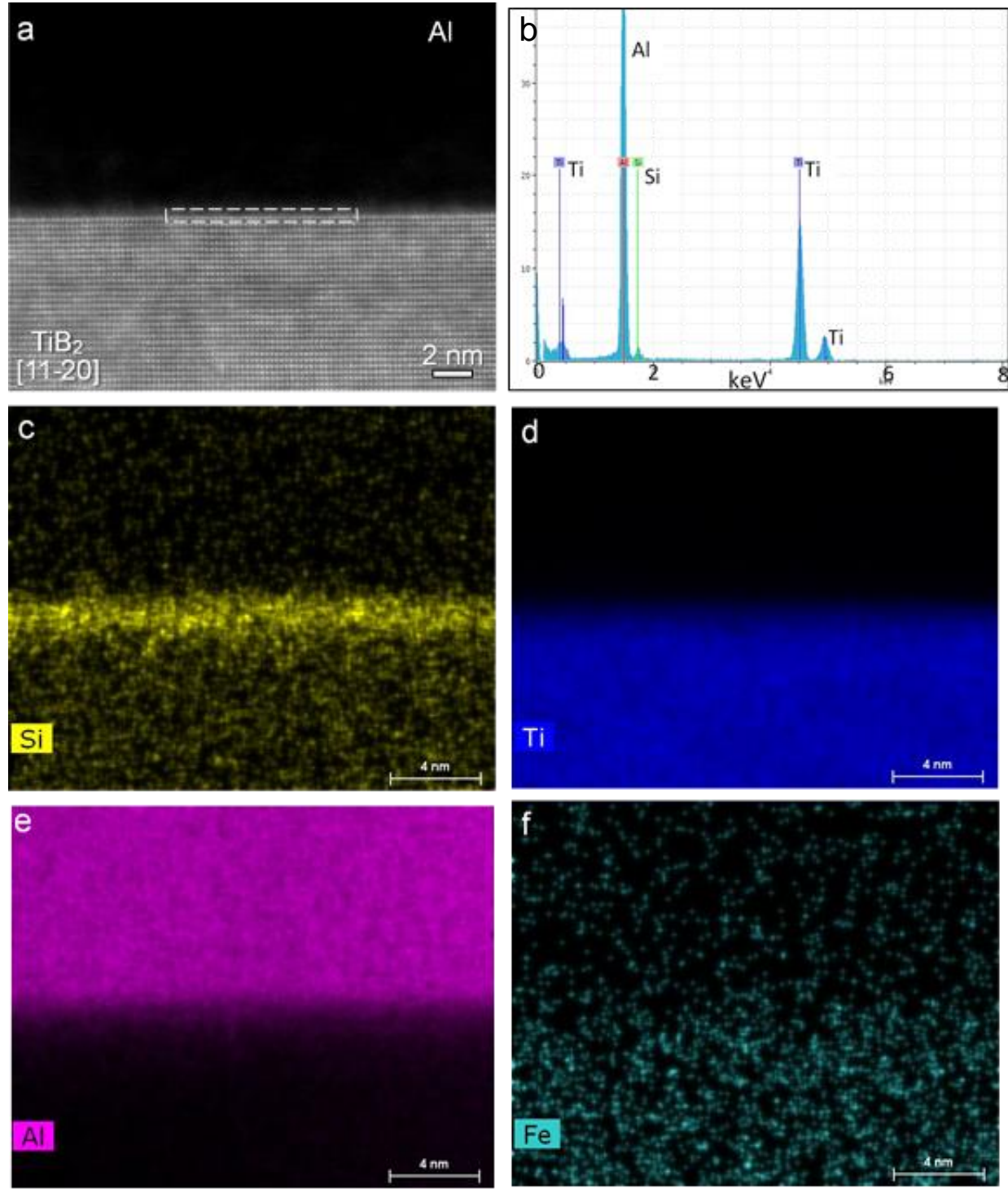

Fig. 9 (a) STEM Z-contrast HAADF image of $\mathrm{TiB}_{2} / \mathrm{Al}$ interface in Al-8.4Si alloy sample inoculated with $0.2 \mathrm{wt} \%$ Al-5Ti-1B grain refiner; (b) Super-X EDS spectrum taken from the local region marked in (a) at the interface, and (c-f) Super-X EDS elemental mapping of (c) Si (yellow), (d) Ti (blue), (e) Al (purple) and (f) Fe (cyan) showing Si segregation at the interface.

\section{Discussion}

4.1 Facilitating TEM examination of nucleants by melt filtration

It is well accepted by the community that a well-defined OR observed by TEM is a direct evidence of nucleation of a solid on a nucleant. However, the difficulty comes from the 

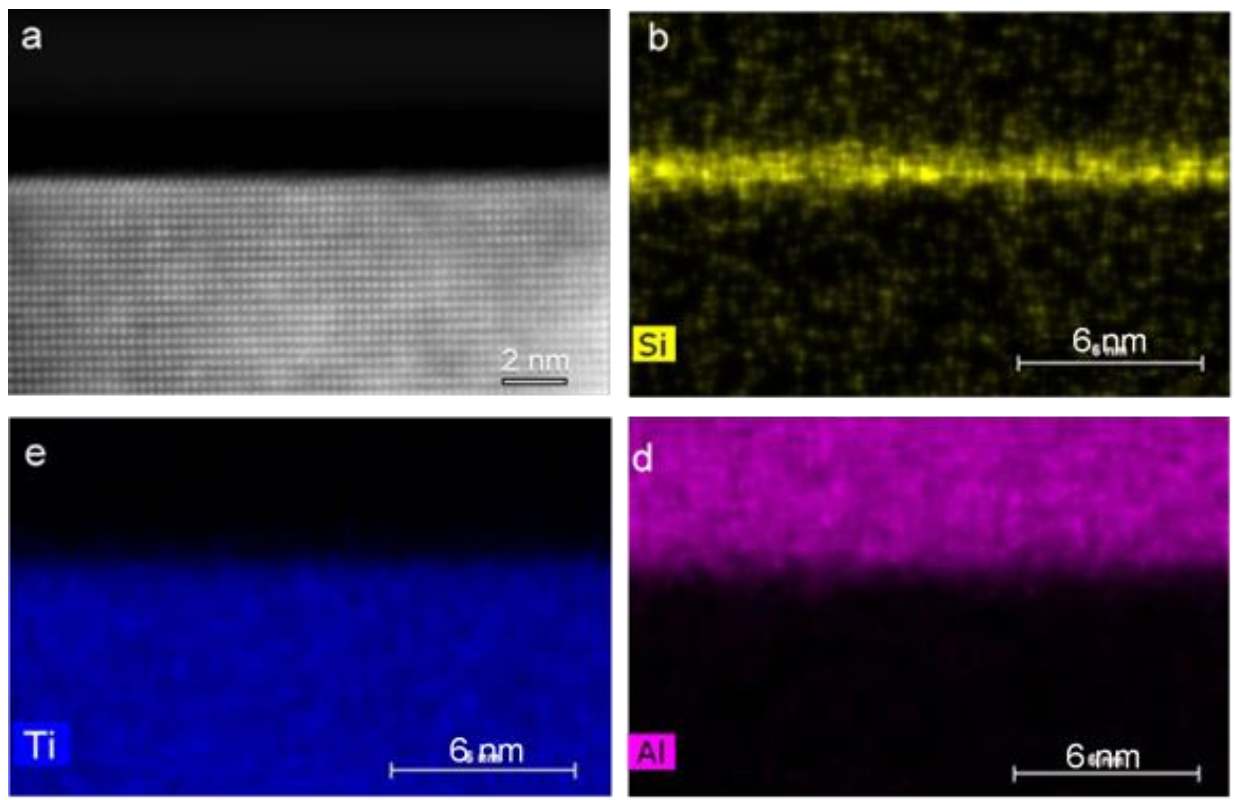

371 Fig. 10 (a) High resolution STEM HAADF image across $\mathrm{TiB}_{2} / \alpha \mathrm{Al}$ interface viewed along [1 1 $\left.\begin{array}{lll}372 & -2 & 0\end{array}\right] \mathrm{TiB}_{2}$ zone direction showing partially dissolved $\mathrm{Al}_{3} \mathrm{Ti}$ 2DC layer on the $\left(\begin{array}{llll}0 & 0 & 0 & 1\end{array}\right)$ surface 373 of the $\mathrm{TiB}_{2}$ particle collected from Al-2.0Si melt, and (b-d) Super-X EDS elemental mapping 374 of (b) $\mathrm{Si}$ (yellow), (c) $\mathrm{Ti}$ (blue) and (d) $\mathrm{Al}$ (purple) across the $\mathrm{TiB}_{2} / \alpha \mathrm{Al}$ interface showing that 375 Si segregation is independent of the $\mathrm{Al}_{3} \mathrm{Ti} 2 \mathrm{DC}$.
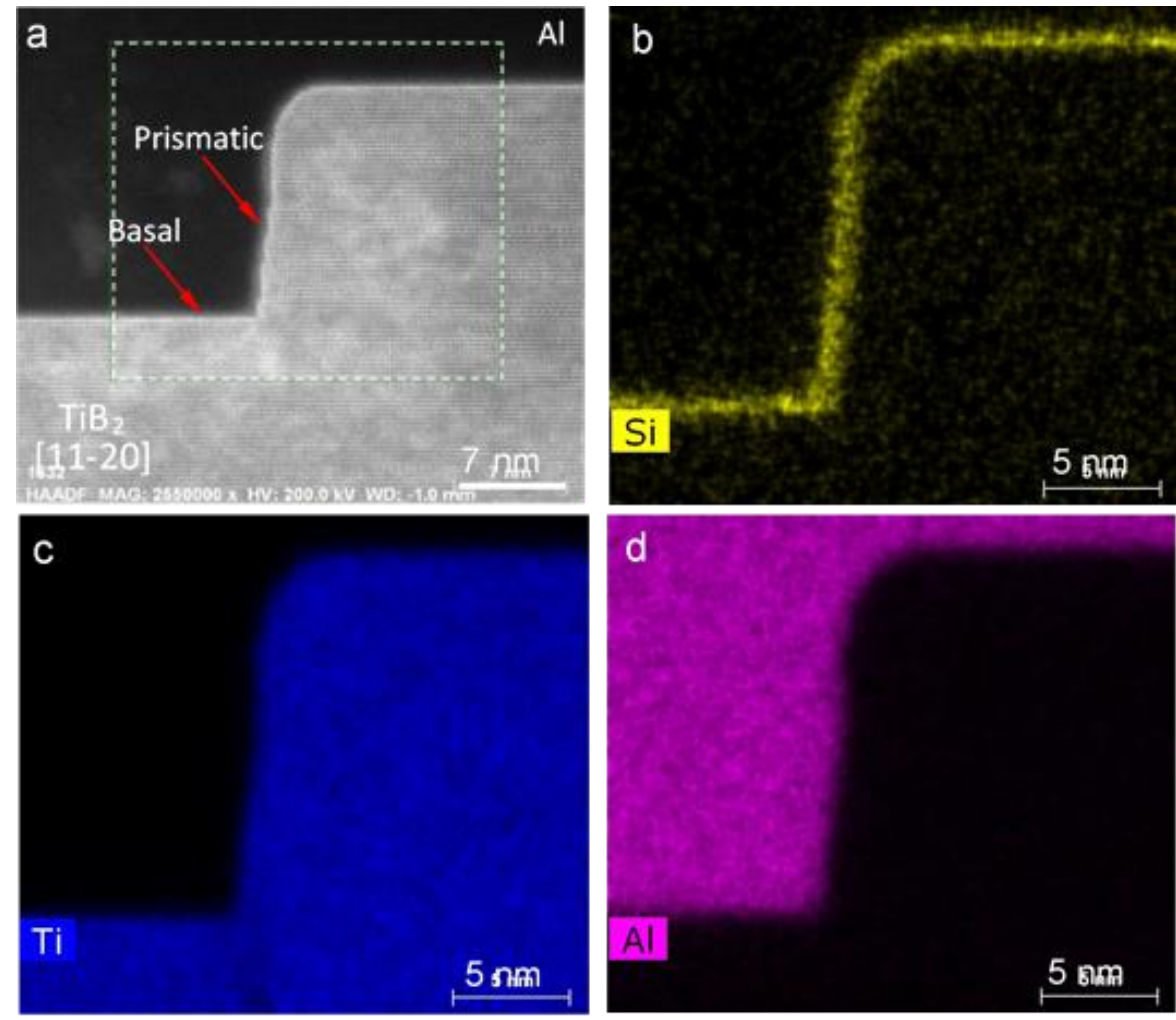

378 Fig. 11 (a) STEM HAADF image of $\mathrm{TiB}_{2} / \mathrm{Al}$ interface in Al-8.4Si alloy inoculated with 0.2 wt\% 379 Al-5Ti-1B grain refiner, and (b-d) Super-X EDS mapping of (b) Si (yellow), (c) Ti (blue) and 380 (d) $\mathrm{Al}$ (purple) across the $\mathrm{TiB}_{2} / \alpha \mathrm{Al}$ interface, showing Si segregation on both $\left\{\begin{array}{llll}0 & 0 & 0 & 1\end{array}\right\}$ basal 381 and $\left\{\begin{array}{llll}1 & 0 & -1 & 0\end{array}\right\}$ prismatic surfaces of $\mathrm{TiB}_{2}$. 
preparation of thin foil specimens for TEM examination. We take $\mathrm{TiB}_{2}$ particles in Al-alloys as an example to demonstrate the challenge. If $\mathrm{a} \mathrm{TiB}_{2}$ particle (say $0.5 \mu \mathrm{m}$ in size) has nucleated an $\mathrm{Al}$ grain (say $200 \mu \mathrm{m}$ in size), it would sit inside the $\mathrm{Al}$ grain. The probability to find this $\mathrm{TiB}_{2}$ particle on a 2D sectioning using the traditional metallography technique would be lower than one in a million, even lower probability to find this $\mathrm{TiB}_{2}$ particle in the limited electrontransparent regions around the perforation of a $\phi 3 \mathrm{~mm}$ disc for TEM examination. This explains why there has been no success in obtaining such an OR by TEM to evidence nucleation in the history of Al-Ti-B master alloys until the mid-1990s. Schumacher and Greer used devitrification of an Al-based metallic glass containing a high density of $\mathrm{TiB}_{2}$ particles as an analogue to the nucleation of $\alpha-\mathrm{Al}$ on $\mathrm{TiB}_{2}$, and obtained successfully the first HRTEM images of $\mathrm{TiB}_{2} / \mathrm{Al}$ interface in this analogue alloy. [66, 67] Successful examination of $\mathrm{TiB}_{2} / \mathrm{Al}$ interface only became a routine when the melt filtration technique was used for TEM sample preparation in 2015. [8]

Pressurized melt filtration, as described previously, allows a significant increase of $\mathrm{TiB}_{2}$ particle number density in a localized region of the melt, but it does not change either the particle potency or melt composition. According to the recent understanding of early stages of solidification, [68] the heterogeneous nucleation processes of the melt before and after filtering are exactly the same, although the increase in particle number density may leads to an increase grain initiation events, thus a finer grain size. Both increase in $\mathrm{TiB}_{2}$ particle number density and decrease in grain size favor the promotion of the probability of successful TEM samples containing $\mathrm{TiB}_{2} / \mathrm{Al}$ interface. So far, this technique has been successfully deployed to study the mechanisms of grain refinement, [8] Zr-poisoning [36] and Si-poisoning (this work), all related to $\mathrm{TiB}_{2}$ particles in Al-alloys.

\subsection{Si interfacial segregation and its effect on nucleation}

Interfacial segregation of $\mathrm{Si}$ at the $\mathrm{TiB}_{2} / \mathrm{Al}-\mathrm{Si}$ melt interface is both theoretically plausible and practically feasible. Experimentally, Si segregation has been observed at $\mathrm{TiB}_{2} /$ melt interfaces in the literature under various conditions. [37, 52-54, 69] Khalifa et al observed Si segregation on surfaces of various inclusions in $\mathrm{Al}$ melt, including $\mathrm{TiB}_{2}$ and $\mathrm{Al}_{2} \mathrm{O}_{3}$. [60] Even with a very low concentration as an impurity in $\mathrm{NiAl} / \mathrm{TiB}_{2}$ composite, a Si segregation layer about $\sim 0.6 \mathrm{~nm}$

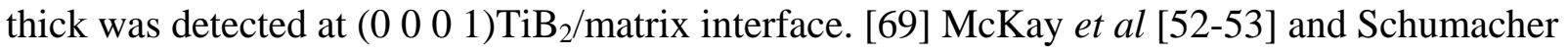
et al [54] also observed Si segregation on the surface of $\mathrm{TiB}_{2}$ in amorphous Al-Si-Ni and Al$\mathrm{Cu}-\mathrm{Ni}-\mathrm{Si}$ alloys. It is confirmed in this work that $\mathrm{Si}$ segregates to both the basal and prismatic surfaces of $\mathrm{TiB}_{2}$ particles in Al-Si alloy melts (Figures 9, 10 and 11). Theoretically, interfacial segregation is driven by reduction of interfacial energy and can be described by the Gibbs adsorption isotherm. [70] Solute segregation at substrate/liquid interface has been demonstrated to change both interfacial energies and the wetting behavior, and therefore affects heterogeneous nucleation behavior. [71-73] Recently, Men and Fan [74] have applied the Gibbs adsorption isotherm to analyze solute segregation at substrate/liquid interfaces and showed that the interfacial solute segregation is governed by i) the difference in interfacial energies between the pure solute/substrate and pure solvent/substrate interfaces, ii) the heat of mixing of the solution, and iii) the difference in entropies of fusion between pure solute and solvent. Due to the lack of relevant input data in the literature, an accurate prediction of Si 
segregation at the $\mathrm{TiB}_{2} / \mathrm{Al}-\mathrm{Si}$ melt interface is not possible. However, a qualitative analysis using the above model [74] does suggest that a significant amount of excess Si can segregate at the $\mathrm{TiB}_{2} / \mathrm{Al}-\mathrm{Si}$ melt interface. The higher the Si concentration in the melt, the more enrichment of $\mathrm{Si}$ at the interface is resulted.

Si segregation at the $\mathrm{TiB}_{2} / \mathrm{Al}$-Si melt interface leads to the formation of a 2-dimetional solution (2DS). Under the experimental conditions of this work, the high resolution TEM and STEM examination has confirmed that there is no formation of either 2D compound (2DC) or 3D bulk phase at the $\mathrm{TiB}_{2} / \alpha \mathrm{Al}$ interface (Figures 4 to 8 ), although $\mathrm{Si}$ segregation is clearly observed at the interface. According to the Gibbs adsorption isotherm, solute segregation driven by interfacial energy reduction occurs only in one or two atomic layers. It is therefore believed that $\mathrm{Si}$ enrichment at the interface is a 2-dimetional solution (2DS). In addition, it seems that the formation of Si-enriched 2DS occurs only in Al-Si melt containing sufficiently high $\mathrm{Si}$ concentration, since notable $\mathrm{Si}$ segregation at the $\mathrm{TiB}_{2} /$ melt interface was not observed in CP$\mathrm{Al}$ which contains about $0.03 \% \mathrm{Si}$ as one of the main impurities. [8, 36] This is different from the cases of interfacial segregation of $\mathrm{Ti}$ or $\mathrm{Zr}$, where ordered $\mathrm{Al}_{3} \mathrm{Ti} 2 \mathrm{DC}$ [8] and $\mathrm{Ti}_{2} \mathrm{Zr} 2 \mathrm{DC}$ [36] were observed at the $\mathrm{TiB}_{2} / \alpha \mathrm{Al}$ interface at low concentrations of $\mathrm{Ti}$ or $\mathrm{Zr}$ in the melt, respectively. The formation of Si-enriched $2 \mathrm{DS}$ at the $\mathrm{TiB}_{2} / \mathrm{Al}-\mathrm{Si}$ melt interface is expected to play an important role in modifying the surface of $\mathrm{TiB}_{2}$ particles, and therefore their potency for heterogeneous nucleation.

An important phenomenon revealed in this work is the dissolution of $\mathrm{Al}_{3} \mathrm{Ti}$ 2DC layer which was formed on the $\mathrm{TiB}_{2}$ surface during the fabrication of the commercial Al-5Ti-1B grain refiner. [8] The $\mathrm{Al}_{3} \mathrm{Ti} 2 \mathrm{DC}$ layer is at least kinetically stable in CP-Al melt, with its dissolution rate in $\mathrm{CP}-\mathrm{Al}$ being so slow that a visible effect on grain refinement was observed only after isothermal holding of the inoculated melt for a period of time up to 78 hours at $800^{\circ} \mathrm{C}$. [8] However, it is clear from this work that the stability of $\mathrm{Al}_{3} \mathrm{Ti} 2 \mathrm{DC}$ layer is considerably reduced when sufficiently high $\mathrm{Si}$ content is present in the $\mathrm{Al}$ melt. The $\mathrm{Al}_{3} \mathrm{Ti} 2 \mathrm{DC}$ layer is readily observed to remain on some $\mathrm{TiB}_{2}$ particles collected from Al-2.0Si melt (Figures 8 and 10) but hardly found on the surface of those $\mathrm{TiB}_{2}$ particles collected from Al-8.4Si melt (Figures 7 and 9). This fact indicates that the $\mathrm{Al}_{3} \mathrm{Ti}$ 2DC layer becomes thermodynamically and/or kinetically unstable and dissolves faster in a higher Si melt than in a lower Si melt. Furthermore, Figures 5 and 6 show that a well-defined OR1 and a slightly deviated OR2 between $\mathrm{TiB}_{2}$ and $\alpha \mathrm{Al}$ are found at low Si content (2.0\%), but no defined OR is observed at high Si contents $(8.4 \%)$ in this study, suggesting that a fewer number of $\mathrm{TiB}_{2}$ particles had participated in grain initiation of $\alpha \mathrm{Al}$ in the high $\mathrm{Si}$ melt, in comparison with that in the low $\mathrm{Si}$ melt. As the $\mathrm{Al}_{3}$ Ti 2DC layer is on the Ti-terminated $\left(\begin{array}{llll}0 & 0 & 0 & 1\end{array}\right) \mathrm{TiB}_{2}$ surface, the dissolution rate is actually dependent on the local Si content at the interface, which is expected to be much higher than that in the bulk melt due to the Si interfacial segregation. With a given level of Al5Ti-1B addition and thus a fixed total number of the $\mathrm{TiB}_{2}$ particles in the melt, more $\mathrm{TiB}_{2}$ particles will lose their $\mathrm{Al}_{3} \mathrm{Ti}$ 2DC layer when Si concentration is higher due to the correspondingly faster dissolution rate, and then the number fraction of those unaffected $\mathrm{TiB}_{2}$ particles decreases. In comparison with $\mathrm{Zr}$ effect on stability of the $\mathrm{Al}_{3} \mathrm{Ti} 2 \mathrm{DC}$, dissolution of the $\mathrm{Al}_{3} \mathrm{Ti}$ 2DC layer in Al-Si melt requires a much higher Si concentration and the dissolution rate is dependent on $\mathrm{Si}$ content, whilst $580 \mathrm{ppm}(0.058 \%) \mathrm{Zr}$ in $\mathrm{Al}$ melt is sufficient to make the $\mathrm{Al}_{3} \mathrm{Ti}$ 2DC layer dissolve completely at a similar temperature. [36] 
Dissolution of $\mathrm{Al}_{3} \mathrm{Ti} 2 \mathrm{DC}$ layer results in a reduced potency of $\mathrm{TiB}_{2}$ particles for heterogeneous nucleation of $\alpha \mathrm{Al}$. Nucleation and subsequent grain initiation events are dependent on the exact physical and chemical characteristics of the nucleant particles introduced to the alloy melt from grain refiner, and their subsequent interactions with the melt. After dissolution of the preexisting $\mathrm{Al}_{3} \mathrm{Ti}$ 2DC layer, heterogeneous nucleation of $\alpha \mathrm{Al}$ takes place directly on the $\left(\begin{array}{llll}0 & 0 & 0 & 1\end{array}\right)$ surface of $\mathrm{TiB}_{2}$, and the crystallographic matching is between $\left\{\begin{array}{llll}0 & 0 & 0 & 1\end{array}\right\} \mathrm{TiB}_{2}$ and $\left\{\begin{array}{llll}1 & 1 & 1\end{array}\right\} \alpha \mathrm{Al}$ according to OR1. The original small lattice misfit $0.09 \%$ at the interface between $\left(\begin{array}{lll}1 & 1 & 1\end{array}\right) \alpha \mathrm{Al}$ and $\mathrm{Al}_{3} \mathrm{Ti}$ 2DC now becomes much larger (-4.22\%) between $\left(\begin{array}{llll}0 & 0 & 0 & 1\end{array}\right) \mathrm{TiB}_{2}$ and $\left(\begin{array}{lll}1 & 1 & 1\end{array}\right) \alpha \mathrm{Al}\left[\begin{array}{l}8 \text {, } \\ \text {, }\end{array}\right.$ 36]. The lattice misfit is even larger (more negative) between $\mathrm{TiB}_{2}$ and Al-Si 2DS because the lattice parameter of $\alpha \mathrm{Al}$ will be reduced when $\mathrm{Si}$ is dissolved in it. For instance, the lattice misfit is increased to $-4.30 \%$ as the lattice parameter $0.4049 \mathrm{~nm}$ for pure $\mathrm{Al}$ decreases to 0.4047 $\mathrm{nm}$ for Al-0.97Si solid solution. [75] Consequently, the original $\mathrm{TiB}_{2}$ particles in the grain refiner lost their potency for heterogeneous nucleation of $\alpha \mathrm{Al}$ in $\mathrm{Al}-\mathrm{Si}$ melt with high enough Si contents.

\subsection{Mechanism of Si poisoning}

Based on the previous analysis, a new mechanism for Si poisoning can be postulated here:

- Preferential interfacial segregation of Si leads to enrichment of Si at the $\mathrm{TiB}_{2} / \mathrm{Al}-\mathrm{Si}$ melt interface. The higher the Si concentration in the melt, the more enrichment of Si at the interface is;

- The pre-existing $\mathrm{Al}_{3} \mathrm{Ti} 2 \mathrm{DC}$ layer on the $\mathrm{TiB}_{2}$ surface dissolves gradually in the melt, resulting in a loss of nucleation potency for the $\mathrm{TiB}_{2}$ particles. The dissolution rate of the 2DC layer increases with the increase of Si content at the interface;

- The overall effect is a reduced total number of potent (at original state) $\mathrm{TiB}_{2}$ particles available for heterogeneous nucleation and grain initiation of $\alpha \mathrm{Al}$, and hence an increased grain size.

This mechanism for Si poisoning is consistent with the previous experimental observations reported in the literature. Previous experiments and this work showed that, upon Si poisoning, the minimum grain size of Al-Si alloys appeared at $\sim 3 \% \mathrm{Si}$. This is in agreement with the above mechanism. When Si content is less than 3\%, the dissolution rate of $\mathrm{Al}_{3} \mathrm{Ti} 2 \mathrm{DC}$ is slow and the majority of the added $\mathrm{TiB}_{2}$ particles are not affected or only partially affected. Therefore, the number of $\mathrm{TiB}_{2}$ particles reserving its original state is sufficient for grain refinement. In this case, growth restriction will prevail over Si poisoning, giving rise to a marginal decrease in grain size with increasing Si content until 3\% Si. With further increase in Si content, Si interfacial segregation increases and thus the dissolution of $\mathrm{Al}_{3} \mathrm{Ti} 2 \mathrm{DC}$ layer becomes faster, resulting in a rapid decrease in the number density of the potent $\mathrm{TiB}_{2}$ particles, and therefore Si poisoning effect prevails over the growth restriction, leading to an increase in grain size.

The experimental observation of defined ORs between $\mathrm{TiB}_{2}$ and $\mathrm{Al}$ (Figures 5 and 6) and dissolution of $\mathrm{Al}_{3} \mathrm{Ti} 2 \mathrm{DC}$ (Figures 7-8) in this work suggest that the number density of potent nucleant particles decreases with increasing Si content beyond 3\%. Khalifa et al [60] showed that, in Al-Si alloys containing 0.3-0.9\% Si, most of $\mathrm{TiB}_{2}$ particles observed were located 
within $\mathrm{Al}$ grains rather than the grain boundaries or the inter-dendritic regions. In contrast, more $\mathrm{TiB}_{2}$ particles in Al-6.4Si alloy were found to locate in inter-dendritic regions, confirming that the $\mathrm{TiB}_{2}$ particles were inactive nucleant particles in the high-Si alloys. Recently, in-situ observation using synchrotron radiation technology showed directly that nucleation events decreased with increasing Si content in $\mathrm{TiB}_{2}$-inoculated Al-Si alloys. [34] In Al-Si alloys inoculated with $0.33 \% \mathrm{Al}-3 \mathrm{Ti}-1 \mathrm{~B}$, the nucleation frequency was found to be reduced by two order of magnitude from $137 \mathrm{~s}^{-1}$ to $1.1 \mathrm{~s}^{-1}$ when $\mathrm{Si}$ content increased from $1.0 \%$ to $9.0 \%$. [34]

This mechanism also explains the dependence of Si poisoning on holding time and the addition level of Al-Ti-B grain refiner. [28, 32] Abdel-Reihim et al found that, with 0.1\% Al-5Ti-1B addition, the grain size of Al-3.5Si alloy increased from about $240 \mu \mathrm{m}$ to $320 \mu \mathrm{m}$ when holding time increases from $10 \mathrm{~min}$. to $60 \mathrm{~min}$.. [28] Kori et al [32] showed that, the higher the Si content $(>7 \%)$ and the longer the holding time, the larger the grain size was. For instance, the grain size of Al-10Si alloy inoculated with $0.2 \%$ Al-5Ti-1B was about $260 \mu \mathrm{m}$ and $650 \mu \mathrm{m}$ for holding times of $5 \mathrm{~min}$. and $120 \mathrm{~min}$., respectively. [32] In addition, they found that, with a high level of grain refiner addition, for instance $0.6 \%$ (6 times of the standard $0.1 \%$ ), [32] grain refinement was achieved for high Si Al-Si alloys. The reason for stronger Si poisoning at a longer holding time is because longer holding time leads to more impotent $\mathrm{TiB}_{2}$ particles and hence larger grain size. However, this decrease in number density of potent particles can be compensated by increased level of grain refiner addition.

Si poisoning was also reported to occur in un-inoculated Al-Si alloys with the minimum grain size occurring at a similar Si content $(\sim 3 \%)$ to that in the inoculated alloys. [26, 29-31, 34] Si poisoning in un-inoculated Al-Si alloys is believed to be related to Si interfacial segregation, despite different types of inoculants. As Prasad et al showed, [34] un-inoculated Al-Si alloys also exhibited a significant number of nucleation events, suggesting that nucleation was triggered by random oxide or impurity particles, in spite of their lower and different potencies than that of $\mathrm{TiB}_{2}$. Si could segregate to the interfaces between these oxide particles and $\mathrm{Al}-\mathrm{Si}$ melt, leading to reduction in their potency for nucleation and therefore poisoning.

Our previous work $[8,36]$ has shown that $\mathrm{Ti}$ and $\mathrm{Zr}$ atoms in $\mathrm{Al}$ melts segregate preferentially to $\mathrm{TiB}_{2} / \alpha \mathrm{Al}$ interface, resulting in the formation of $\mathrm{Al}_{3} \mathrm{Ti} 2 \mathrm{DC}$ or $\mathrm{Ti}_{2} \mathrm{Zr} 2 \mathrm{DC}$ layer, respectively. However, the effect of the two types of 2DC layer on heterogeneous nucleation is just opposite, with $\mathrm{Al}_{3} \mathrm{Ti} 2 \mathrm{DC}$ enhancing nucleation while $\mathrm{Ti}_{2} \mathrm{Zr}$ 2DC impeding nucleation. In this work, $\mathrm{Si}$ segregation at $\mathrm{TiB}_{2} / \mathrm{Al}-\mathrm{Si}$ melt interface results in dissolution of $\mathrm{Al}_{3} \mathrm{Ti}$ 2DC, with the dissolution rate being dependent on Si concentration at the interface. It is demonstrated that interfacial segregation of solute elements can significantly alter the behavior of the substrate during heterogeneous nucleation process. From nucleation point of view, segregation of solute elements leads to either enhancement or impediment of heterogeneous nucleation. This makes it possible to manipulate the nucleation process by modification of substrates through deliberate segregation of certain elements.

\section{Conclusions}

1) Al-5Ti-1B grain refiner is not effective for grain refining $\mathrm{Al}-\mathrm{Si}$ alloys with $\mathrm{Si}$ concentration higher than $3 \%$. Under the TP-1 solidification conditions of this work, the 
grain size of $\alpha \mathrm{Al}$ is increased from $195 \pm 22 \mu \mathrm{m}$ to $867 \pm 78 \mu \mathrm{m}$ as Si content is increased from $2 \%$ to $10 \%$ in the hypoeutectic Al-Si alloys inoculated with $0.2 \%$ of Al-5Ti-1B grain refiner. The increase in grain size with Si content was accompanied by a morphological transition from cellular to dendritic for the primary $\alpha \mathrm{Al}$ phase.

2) A well-defined orientation relationship (OR) between $\mathrm{TiB}_{2}$ and $\alpha \mathrm{Al},\left(\begin{array}{llll}0 & 0 & 0 & 1\end{array}\right)\left[\begin{array}{llll}1 & 1 & -2 & 0\end{array}\right]$ $\mathrm{TiB}_{2} / /\left(\begin{array}{lll}1 & 1 & 1\end{array}\right)\left[\begin{array}{lll}0 & -1 & 1\end{array}\right] \alpha \mathrm{Al}$, is observed for the $\mathrm{TiB}_{2}$ particles collected from Al-2.0Si melt, but no defined OR is found for the $\mathrm{TiB}_{2}$ particles in Al-8.4Si alloy melt.

3) Si segregates preferentially to the solid/liquid interface between $\mathrm{TiB}_{2}$ and $\mathrm{Al}-\mathrm{Si}$ melt on both the $\left\{\begin{array}{llll}0 & 0 & 0 & 1\end{array}\right\}$ basal and $\left\{\begin{array}{llll}1 & 0 & -1 & 0\end{array}\right\}$ prismatic surfaces of $\mathrm{TiB}_{2}$ particles.

4) The $\mathrm{Al}_{3} \mathrm{Ti} 2 \mathrm{DC}$ layer formed on the $\mathrm{TiB}_{2}$ surface during the grain refiner production process becomes unstable in Al-Si melt and therefore dissolves into the melt with time. The 2DC layer is readily found to remain on the surface of some of the $\mathrm{TiB}_{2}$ particles in low $\mathrm{Si}(2.0 \%)$ samples but not observed on the particles in high $\mathrm{Si}(8.4 \%)$ samples, showing an increased dissolution rate at high Si contents.

5) There is no evidence of formation of $2 \mathrm{D}$ or $3 \mathrm{D}$ bulk phase at the $\mathrm{TiB}_{2} / \alpha \mathrm{Al}$ interface under the experimental conditions of this work. Segregated Si atoms stay in a thin layer of AlSi melt at the interface as 2 dimensional solution (2DS).

6) A new mechanism for Si poisoning is proposed: Preferential interfacial segregation of $\mathrm{Si}$ leads to enrichment of $\mathrm{Si}$ at the $\mathrm{TiB}_{2} / \mathrm{Al}-\mathrm{Si}$ melt interface, and this in turn makes the preexisting $\mathrm{Al}_{3} \mathrm{Ti} 2 \mathrm{DC}$ on the $\mathrm{TiB}_{2}$ surface unstable and thus dissolve gradually in the melt resulting in a loss of its nucleation potency. The overall effect is a reduced total number of potent $\mathrm{TiB}_{2}$ particles available for heterogeneous nucleation and grain initiation of $\alpha \mathrm{Al}$, and hence an increased grain size.

7) This new mechanism is consistent with the experimental findings in the literature, such as grain size minimum at $3 \% \mathrm{Si}$, dependence of grain size on holding time and levels of grain refiner addition, Si poisoning of un-inoculated Al-Si melts, and so on.

\section{Acknowledgements}

The EPSRC is gratefully acknowledged for providing financial support under grant number EP/N007638 /1.

\section{References}

1. A. Cibula, J. Inst. Metals, 1951-52, vol. 80, pp 1-16.

2. D.G. McCartney, Inter. Mater. Rev., 1989, vol. 34, pp. 247-260.

3. M. Easton and D. StJohn, Metall. Mater. Trans. A, 1999, vol. 30A, pp. 1613-1623.

4. B.S. Murty, S.A. Kori and M. Chakraborty, 2002, Inter. Mater. Rev., vol. 47, pp. 3-47.

5. T.E. Quested, Mater. Sci. Tech., 2004, vol. 20, pp. 1357-1369.

6. L. Greer, J. Chem. Phys., 2016, vol. 145, pp. 211704.1-211704.14.

7. M.A. Easton, M. Qian, A. Prasad, and D.H. StJohn, Curr. Opin. Solid State Mater. Sci., 2016, vol. 20, pp. 13-24. 
8. Z. Fan, Y. Wang, Y. Zhang, T. Qin, X.R. Zhou, G.E. Thompson, T. Pennycook and T. Hashimoto, Acta Mater., 2015, vol. 84, pp. 292-304.

9. G.P. Jones and J. Pearson, Metall. Trans. B, 1976, vol. 7B, pp. 223-234.

10. A.A. Abdel-Hamid, Z. Metallkd., 1989, vol. 80, pp. 643-647.

11. M. Johnsson, Z. Metallkd. 1994, vol. 85, pp. 786-789.

12. J.A. Spittle and S. Sadli, Cast Metals, 1995, vol. 8, pp. 247-253.

13. A. Arjuna Rao, B.S. Murty and M. Chakraborty, Mater. Sci. Technol., 1997, vol. 13, pp. 769-777.

14. M.A. Kearns, P. Cooper, Mater. Sci. Technol., 1997, vol. 13, pp. 650-654.

15. M.E.J. Birch, in: C. Baker, P.J. Gregson, S.J. Harris and C.J. Peers (eds.), Aluminiumlithium Alloys III, The Institute of Metals, London, 1986, pp. 152-158.

16. C.R. Chakravorty and M. Chakraborty, Cast Metals, 1991, vol. 4, pp. 98-100.

17. A. Arjuna Rao, B.S. Murty and M. Chakraborty, Metall. Mater. Trans. A, vol. 27A, pp. 791-800.

18. A. Arjuna Rao, B.S. Murty and M. Chakraborty, Int. J. Cast Met. Res., 1996, vol. 9, pp. $125-132$.

19. J. A. Spittle, Inter. J Cast Metals Res., 2006, vol. 19, pp. 210-222.

20. G.K. Sigworth and M.M. Guzowaski, AFS Trans., 1985, vol. 93, pp. 907-912.

21. M. Johnsson, Z. Metallk., 1994, vol. 85, pp. 781-785.

22. M. Johnsson and L. Backerud, Z. Metallk., 1996, vol. 87, pp. 216-220.

23. P. Hoefs, W. Reif and W. Schneider, Giesserei, 1994, vol. 81, pp. 398-406.

24. M. Abdel-Reihim, N. Hess, W. Reif and M.E.J. Birch, J. Mater. Sci., vol. 22, pp. 213-218.

25. J.A. Spittle, J.M. Keeble and M. Al Meshhedani, in: R. Huglen (ed.), Light Metals 1997, TMS, Warrendale PA, 1997, pp. 795-800.

26. J.E.C. Hutt, D.H. StJohn, L. Hogan and A.K. Dahle, Mater. Sci. Technol., 1999, vol. 15, pp. 495-500.

27. L. Backerud and M. Johnsson, in: W. Hale (ed.), Light Metals 1996, TMS, Anaheim CA, 1996, pp. 679-685.

28. M. Abdel-Reihim, N. Hess, W. Reif and M.E.J. Birch, J. Mater. Sci., 1987, vol. 22, pp. 213-218.

29. Y.C. Lee, A.K. Dahle, D.H. StJohn and J.E.C. Hutt, Mater. Sci. Eng. A, 1999, vol. 259, pp. 43-52.

30. Y. Birol, Inter. J. Cast Metals Res., 2013, vol. 26, pp. 22-27.

31. Y. Birol, Mater. Sci. Technol. 2012, vol. 28, pp. 385-389.

32. S.A. Kori, B.S. Murty and M. Chakraborty, Mater. Sci. Tech., 1999, vol. 15, pp. 986-992.

33. S.A. Kori, V. Auradi, B.S. Murty and M. Chakraborty, Mater. Forum, 2005, vol. 29, pp. 387-393.

34. A. Prasad, S.D. McDonald, H. Yasuda, K. Nogita and D.H. StJohn, J. Cryst. Growth, 2015, vol. 430, pp. 122-137.

35. D. Qiu, J.A. Taylor, M-X. Zhang and P.M. Kelly, Acta Mater. 2007, vol. 55, pp. 14471456.

36. Y. Wang, C.M. Fang, L. Zhou, T. Hashimoto, X. Zhou, Q.M. Ramasse and Z. Fan, Acta Mater., 2019, vol. 164, pp. 428-439.

37. P.S. Mohanty and J.E. Gruzleski, Acta Mater, 1996, vol. 44, pp. 3749-3760.

38. G.S.V. Kumar, B.S. Murty and M. Chakraborty, J. Alloys Compd., 2009, vol. 472, pp. 112- 
120.

39. T. Wang, H. Fu, Z. Chen, J. Xu, J. Zhu, F. Cao and T. Li, J. Alloys Compd., 2012, vol. 511, pp. 45-49.

40. Y. Birol, Mater. Sci. Technol., 2012, vol. 28, pp. 481-486.

41. S.A. Kori, B.S. Murty and B.S. Chakraborty., Mater. Sci. Eng. A, 2000, vol. 283, pp. 94104.

42. L. Yu, X. Liu, Z. Wang and X. Bian, J. Mater. Sci., 2005, vol. 40, pp. 3865-3867.

43. H. Zhao, H. Bai, J. Wang and S. Guan, Mater. Charact., 2009, vol. 60, pp. 377-383.

44. P. Li, S. Liu, L. Zhang and X. Liu, Mater. Design, 2013, vol. 47, pp. 522-528.

45. Y. Birol, J. Alloys Compd. 2012, vol. 513, pp. 150-153.

46. Y. Birol, Mater. Sci. Tech., 2012, vol. 28, pp. 363-367.

47. Z. Chen, H. Kang, G. Fan, J. Li, Y. Lu, J. Jie, Y. Zhang, T. Li, X. Jian and T. Wang, Acta Mater., 2016, vol. 120, pp. 168-178.

48. M. Nowak, L. Bolzoni and N. Hari Babu, Mater. Design, 2015, vol. 66, pp. 366-375.

49. L. Bolzoni, M. Nowak and N. Hari Babu, Mater. Design, 2015, vol. 66, pp. 376-383.

50. L. Bolzoni and N. Hari Babu, Metall. Mater. Trans. A, 2019, vol. 50A, pp. 746-756.

51. M.E.J. Birch, P. Fisher, in: T. Sheppard (ed.), Aluminium Technology 86, The Institute of Metals, London, 1986, pp. 117-124.

52. B.J. McKay, Heterogeneous nucleation in Al-Si alloys, $\mathrm{PhD}$ Thesis, University of Oxford, Oxford, UK, 2001.

53. B.J. McKay, P. Cizek, P. Schumacher and K.A.Q. O'Reilly, Mater. Sci. Eng. A, 2001, vol. 304-306, pp. 240-244.

54. P. Schumacher and B. J. McKay, J. Non-Cryst. Solids, 2003, vol. 317, pp. 123-128.

55. T.E. Quested, A.T. Dinsdale and A.L. Greer, Mater. Sci. Tech., 2006, vol. 22, pp. 11261134.

56. P.S. Cooper, A. Hardman, D. Boot and E. Burhop, in: P. Crepeau (ed.), Light Metals 2003, TMS, Warrendale PA, 2003, pp. 923-928.

57. T.E. Quested, A.T. Dinsdale and A.L. Greer, Acta Mater., 2005, vol. 53, pp. 1323-1334.

58. M. Johnsson, Thermochim. Acta, 1995, vol. 256, pp. 107-121.

59. J.E.C. Hutt, A.K. Dahle, Y.C. Lee and D.H. StJohn, in: C.E. Eckert (ed.), Light Metals 1999, TMS, Warrendale PA, 1999, pp. 685-692.

60. W. Khalifa, F. H. Samuel and J. E. Gruzleski, Metall. Mater. Trans. A, 2004, vol. 35A, pp. 3233-3250.

61. M.A. Easton, A. Prasad and D.H. StJohn, Mater. Sci. Forum, 2014, vol. 794-796, pp. 161166.

62. Standard Test Procedure for Aluminum Alloy Grain Refiners (TP-1), The Aluminum Association, Washington, DC, 1990.

63. Z. Fan, Y. Wang, M. Xia and S. Arumuganathar, Acta Mater., 2009, vol. 57, pp. 48914901.

64. Y. Wang, Z. Fan, X. Zhou and G.E. Thompson, Phil. Mag. Lett., 2011, vol. 91, pp. 516529.

65. A.L. Greer, A.M. Bunn, A. Tronche, P.V. Evans and D.J. Bristow, Acta Mater., 2000, vol. 48, pp. 2823-2835.

66. P. Schumacher and A.L. Greer, Mater. Sci. Eng. A, 1994, vol. A178, pp. 309-313.

67. P. Schumacher and A.L. Greer, Mater. Sci. Eng. A, 1994, vol. A181/A182, pp. 1335-1339. 
684 68. H. Men and Z. Fan, Metall. Mater. Trans. A, 2018, vol. 49, pp. 2766-2777.

685 69. L. Wang and R.J. Arsenault, Metall. Trans. A, 1991, vol. 22A, pp. 3013-3018.

686 70. E. Hondros, M. Seah, S. Hofmann and P. Lejcek, in: R. Cahn, P. Haasen (eds.), Physical 687 Metallurgy, North-Holland, Amsterdam, 1996, pp. 1201-1289.

688 71. J.W. Christian, The theory of transformations in metals and alloys, 3rd ed., Pergamon, $689 \quad$ Oxford, 2002.

690 72. B. Cantor, Philos. Trans. R. Soc. London. A, 2003, vol. 361, pp. 409-417.

691 73. Z. Fan, Metall. Mater. Trans. A, 2013, vol. 44A, pp. 1409-1418.

692 74. H. Men and Z. Fan, Metall. Mater. Trans. A, 2014, vol. 45A, pp. 5508-5516.

693 75. W.B. Pearson, A Handbook of lattice spacings and structures of metals and alloys, $694 \quad$ Pergamon Press, London 1958, p. 382. 